\title{
NOTAS HISTÓRICAS SOBRE LA CAPILLA DE MÚSICA DE LA COLEGIATA DE SANTA MARÍA DE LOS REALES ALCÁZARES DE ÚBEDA, JAÉN (SIGLOS XVI-XVIII)
}

\author{
HISTORICAL NOTES ON THE MUSIC CHAPEL OF THE COLLEGIATE \\ CHURCH OF SANTA MARÍA DE LOS REALES ALCÁZARES IN ÚBEDA (JAÉN) \\ (16th-18th CENTURIES)
}

\author{
Antonio Almagro García \\ Centro Universitario SAFA, Úbeda (Jaén) \\ aalmagro@fundacionsafa.es \\ ORCID ID: 0000-0003-0710-1042 \\ Rosa María Perales Molada \\ Centro Universitario SAFA, Úbeda (Jaén) \\ rperales@fundacionsafa.es \\ ORCID ID: 0000-0002-3534-9224 \\ Isabel Segura Moreno \\ Centro Universitario SAFA, Úbeda (Jaén) \\ isegura@fundacionsafa.es \\ ORCID ID: 0000-0003-1844-6329
}

\begin{abstract}
Resumen
Este trabajo es un acercamiento al conocimiento de la capilla de música de la antigua colegiata de Santa María de los Reales Alcázares de Úbeda, Jaén (1258-1852), la primera de las tres existentes en la ciudad, a través del estudio y presentación de la documentación conservada en el Archivo Histórico Municipal de Úbeda - en las actas capitulares municipales conservadas de los siglos XVII y XVIII - y en el Archivo Ducal de Medinaceli (Sevilla), en donde recientemente se han localizado las únicas actas capitulares conocidas de la colegial. Las dificultades del estudio vienen marcadas por la lamentable escasez de fuentes documentales que a su vez lleva a la limitada, aunque importante, existencia de bibliografía sobre el tema. Con todo, se aportan datos de enorme interés sobre un aspecto de la historia musical ubetense muy desconocido - objetivo fundamental del estudio-, al tiempo que se abren caminos para nuevas investigaciones como objeto de futuros trabajos.
\end{abstract}

\begin{abstract}
The ancient collegiate church of Santa María de los Reales Alcázares in Úbeda, Jaén (1259-1852) is the oldest of the three existing ones in the town. This study presents 17 th and 18 th century documentation about musicians and musical activites preserved at the Archivo Histórico Municipal of Úbeda and in the Archivo Ducal de Medinaceli (Sevilla), where the chapter records - mostly from the 18th century - of that collegiate church were recently found Even though there is important literature about Úbeda, the scarcity of documentary sources is a great limitation. Thus the new data presented here about Úbeda's musical history opens up the way for future research.
\end{abstract}




\section{Palabras clave}

Úbeda (Jaén), Santa María de los Reales Alcázares de Úbeda, Archivo Histórico Municipal de Úbeda, Archivo Ducal de Medinaceli (Sevilla), siglo XVIII, colegiata, capilla de música, musicología urbana.

\section{INTRODUCCIÓN}

El estudio de la Úbeda de los siglos de la Modernidad se ha venido ampliando en multitud de trabajos publicados en las últimas décadas, contribuyendo a que el conocimiento histórico y artístico de esta ciudad, declarada Patrimonio Mundial por la UNESCO en 2003, esté hoy a la merecida altura de otras muchas. Pero esto no quiere decir que no haya aspectos de su pasado carentes de un necesario conocimiento y reconocimiento, siendo uno de ellos, muy especialmente, el de la música. La realización de anteriores trabajos, el estudio de los fondos del Archivo Histórico Municipal y el reciente descubrimiento de acuerdos capitulares inéditos de la antigua colegiata de Santa María de los Reales Alcázares de Úbeda conservados en el Archivo Ducal de Medinaceli en Sevilla, permiten, aunque sea de forma incompleta y llena de lagunas, acceder a una información de primera mano sobre la organización y actividad de su capilla de música. ${ }^{1}$

La cronología de la documentación que hemos estudiado es de los siglos XVI, XVII y XVIII, pero hacemos un especial hincapié en el XVIII, al cual pertenecen la práctica totalidad de los acuerdos capitulares relativos a dos momentos: el periodo que abarca desde los años cincuenta a los sesenta y el correspondiente a la última déca-

${ }^{1}$ El Archivo Histórico Municipal de Úbeda (A.H.M.Ú.) guarda más de dos mil protocolos notariales, numerosos padrones de repartimiento y la totalidad de las actas capitulares conservadas de estos siglos; esa documentación lógicamente se ha trabajado y consultado a lo largo de muchos años. La colegiata de Santa María de Úbeda, así constituida desde 258 a 1852, es una de las tres existentes en la ciudad desde el siglo XVI, junto a las de la Sacra Capilla de El Salvador y Hospital de Santiago. De su rico archivo colegial, tras la guerra del 36 y años posteriores, únicamente se han conservado: algunos privilegios episcopales y papales que no se relacionan con el objeto de este trabajo, un libro de actas capitulares de principios del siglo XIX y las mencionadas actas capitulares de los siglos XVII y XVIII que se encuentran en el Archivo Ducal de Medinaceli en Sevilla. Creemos que el depósito en ese archivo se debe a la destrucción y dispersión del archivo colegial durante y tras la Guerra Civil, lo que propició un posible error de asignación o su venta.

\section{Keywords}

Úbeda (Jaén), Santa María de los Reales Alcázares in Úbeda, Archivo Histórico Municipal de Úbeda, Archivo Ducal de Medinaceli (Seville), 18th century, collegiate church, music chapel, urban musicology.

da del siglo, cuando ya la colegial no disfrutaba de sus mejores momentos y había caído en un letargo paralelo al de la propia ciudad. Metodológicamente, por consiguiente, el trabajo se ha centrado, por una parte, en el estudio de la documentación conservada en el Archivo Histórico Municipal y en la del Archivo Ducal de Medinaceli y, por otra, en el acercamiento a la bibliografía existente sobre el tema, aunque considerando que había que detenerse en la documentación primaria poco conocida o desconocida. Ciertamente, las fuentes no permiten un estudio diacrónico completo, pero sí hacen posible aportar un buen número de "notas" que al menos amplían lo que se sabe del mundo musical en la Úbeda de la Modernidad, al tiempo que abren otras vías de investigación.

Así pues, nos centraremos, en primer lugar y brevemente, en un acercamiento al contexto urbano; en segundo, a introducir el papel desempeñado por la música en la vida de la ciudad; en tercero, en la justificación de la importancia de Santa María de los Reales Alcázares en la historia de la ciudad y su contexto musical; y, en cuarto y último, en la presentación de la información contenida en las actas capitulares conservadas en Sevilla, completada con la procedente de otras fuentes. De esta manera, esperamos ampliar notablemente el conocimiento de un aspecto ignorado de la historiografía de Úbeda.

\section{CONTEXTUALIZACIÓN: MÚSICA Y CIUDAD EN LA ÚBEDA DE LA EDAD MODERNA}

El estudio de la musicología urbana en Úbeda carece de un deseable desarrollo por las dificultades que le acompañan. La documentación es relativamente abundante, pero dispersa, tangencial e insuficiente para permitir un conocimiento tan completo y profundo como sería deseable. Por ello, asumimos lo expresado por Miguel Ángel Marín:

Con estas severas limitaciones, este trabajo aspira a reconstruir de forma tan completa como sea posible la vida musical de la ciudad de Úbeda durante los siglos XVI a XVIII, un periodo que por comodidad se englobará bajo el nombre de Antiguo Régimen. Frente a la aproximación convencional en musicología que centra 
el interés en una institución (generalmente la catedral) o en un compositor, el objeto de estudio de este trabajo es la ciudad en su conjunto, una perspectiva que se ha venido a denominar "musicología urbana". Esta aproximación reivindica, en esencia, la necesidad de estudiar todas las instituciones urbanas que una forma $\mathrm{u}$ otra participaron en la vida musical (financiando grupos estables de músicos o contratando servicios musicales disponibles en otras instituciones locales) así como de desvelar las relaciones de intercambio y colaboración musicales que entablaron. ${ }^{2}$

Con todo, la presencia en el Archivo Histórico Municipal de Úbeda de padrones de repartimiento, actas capitulares y protocolos notariales, entre otros documentos, de los siglos XVI, XVII y XVIII, así como de un buen número de referencias bibliográficas sobre el tema nos permite hablar de un contexto histórico propicio. ${ }^{3}$ Se constata la presencia de lutiers, organeros, órganos, organistas, músicos, ministriles, sochantres, maestros de capilla y capillas de música. Además, la música aparece asociada al teatro y a las celebraciones festivas de carácter sacro y profano, documentándose las relaciones de las capillas de música con las cofradías, parroquias, conventos y cabildo municipal, así como el uso

2 Miguel Ángel Marín López, “¿Una historia imposible? Música y devoción en Úbeda durante el Antiguo Régimen”, en Úbeda en el siglo XVI, dirigido por Arsenio Moreno Mendoza (Jaén: Fundación Renacimiento y Editora El Olivo, 2002), p. 143.

3 Véanse, entre otros, los siguientes estudios sobre Úbeda en los que basamos nuestros comentarios: Antonio Almagro García, Artistas y artesanos en la ciudad de Úbeda durante el siglo XVII (Jaén: Universidad de Jaén, 2003) y, del mismo autor, Pompa y circunstancia en la Úbeda del siglo XVII (Vida, gentes y espacios) (Jaén: El Olivo, 2005); Antonio Almagro García y Vicente Miguel Ruiz Fuentes, "Arquitectura e imaginería efímera en las celebraciones religiosas del Siglo de Oro Ubetense", en IV Congreso sobre Humanismo y Renacimiento. Seminario sobre Iconología y Simbolismo en el Siglo de Oro, ed. J. Latorre García y Joaquín Montes Bardo (Úbeda: UNED, 1998), pp. 93-110; Marín López, “¿Una historia imposible?, pp. 141-166, y, del mismo autor, "Úbeda", en Diccionario de la música española e hispanoamericana, 10 vols., editado por Emilio Casares Rodicio (Madrid: Sociedad General de Autores y Editores, 2002), vol. 10 (2002), pp. 542-544; y Ginés de la Jara Torres Navarrete, Historia de Úbeda en sus documentos: Linajes y hombres ilustres (Úbeda: Gráficas Minerva, 1999). de la música profana por la nobleza local. En consecuencia, es posible afirmar que la música debió adoptar y desempeñar un papel de enorme presencia e importancia en la Úbeda de la Edad Moderna y, tanto más, posiblemente, como centro que irradiaba y recibía influencias y contactos.

Aunque los siglos XVII y XVIII progresivamente supusieron un periodo de decadencia en todos los ámbitos para esta ciudad y no fue hasta bien entrado el siglo XIX cuando se produjo un florecimiento de las artes y del urbanismo, a finales del siglo XVI, Úbeda constituyó uno de los núcleos urbanos más importantes de Castilla. Junto al comercio, la agricultura y la industria, se llevó a cabo un desarrollo urbanístico que otorgó a la ciudad un carácter señorial; así, se construyeron palacios, casas solariegas, hospitales, conventos, iglesias y capillas que vinieron a configurar casi de forma definitiva a la Úbeda actual como ciudad del Renacimiento. ${ }^{4}$ Junto a este desarrollo y, especialmente, con el de las capillas de música existentes en la ciudad, es necesario destacar que el Concilio de Trento, celebrado entre 1545 y 1563 , le otorgó a la música un carácter especial en las celebraciones litúrgicas (Sesión XXII de 1562) al tiempo que propició - pensamos - una mayor profesionalidad en el ejercicio musical eclesiástico y en el desarrollo de capillas de música con una mayor especialización en obras y artistas. Además del protagonismo de la música en la liturgia, el fenómeno se amplía en las manifestaciones de carácter religioso como el Corpus y también en otras muchas y variadas actividades sociales (como el fin de epidemas) y culturales (es el caso del teatro), celebradas en recintos apropiados o en la calle (generalmente asociadas al ciclo vital de la Monarquía), en las cuales otro tipo de música siempre estuvo presente. 5

Podemos afirmar, por consiguiente, que la presencia de la música en Úbeda durante la Edad Moderna fue un hecho destacado y notable que formó parte de la vida de la ciudad y del sentir y pensar de sus gentes. ${ }^{6}$

${ }^{4}$ Almagro García, Artistas y artesanos en la ciudad de Úbeda durante el siglo XVII.

5 Almagro García y Ruiz Fuentes, "Arquitectura e imaginería efímera en las celebraciones religiosas del Siglo de Oro Ubetense".

6 Véase, de los mismos autores del presente artículo, "Música y ciudad en la Úbeda de la Edad Moderna", Boletín del Instituto de Estudios Giennenses (en preparación), donde se aborda este tema de forma más extensa. 


\section{ACERCA DE LA COLEGIATA DE SANTA MARÍA DE LOS REALES ALCÁZARES DE ÚBEDA}

La bula de nombramiento como colegiata de la hasta entonces Iglesia Mayor Parroquial de Santa María de Úbeda, firmada por el obispo don Pascual en 1259, ya destaca la importancia de este templo:

[...] al ser considerado sin duda alguna el alcázar de Úbeda como insigne entre latinos y bárbaros, debido a su cuantiosa población, a su extensión y abundancia en todo lo necesario, de tal manera que, si no fuese por la proximidad de otros famosos lugares que en este aspecto le perjudican no poco, merecería ser honrado con el honor de una cátedra pontifical, hemos decretado, en cuanto con la ayuda de Dios nos es posible, distinguirlo con el prestigio de un título eclesiástico. ${ }^{7}$

Por otra parte, también queda de manifiesto la situación estratégica e importancia simbólica de la colegial, cuando leemos las palabras de Joaquín Montes Bardo en el prólogo al estudio de Almagro García:

Para la comprensión de esta arquitectura, no podemos obviar este hecho decisivo: Úbeda y Baeza delinean el espacio histórico y geográfico en el que se ensaya la Restauración cristiana de Andalucía a partir de la batalla de las Navas de Tolosa, o de Úbeda, en 1212. Como reflejo, Baeza tiene la primera catedral de Andalucía, y Úbeda la primera colegiata. Ello explica que se emplace en el espacio urbano más significativo de su centro histórico, cuya singularidad ayuda a definir al integrarse perfectamente en la estructura unitaria que se ordena.

Esta relación con la hora fundacional de la ciudad hace de ella la piedra angular de la comunidad cristiana de la que es símbolo; justificando que cada generación haya ido configurando una iglesia mayor diferente, y que la presente sea resultado de todas ellas. Para retener su momento mágico, habría que imaginarla en su primera apariencia, transitando de mezquita a templo cristiano, a medio camino entre Oriente y Occidente. Modificada apenas con el ritual de consagración de las divinas palabras, el agua de la penitencia, el vino de la alegría, la sal de la sabiduría, la ceniza de la humildad y el óleo del espíritu. Y solo como novedad, la erección de un altar con una imagen de La Señora. Así aconteció, primero en Bae-

7 José Higueras Maldonado, Documentos latinos de Úbeda (Jaén: Instituto de Estudios Giennenses, 1975), pp. 49 y siguientes. za y, después de Úbeda, en Jaén, Córdoba y Sevilla. Lo relata Rodrigo Jiménez de Rada testigo y protagonista de los acontecimientos.

Hoy, su visión exterior en el promontorio de una ciudad fronteriza; ceñido el templo por las capillas funerarias de los linajes principales, como disputándose el espacio sacro en su aproximación al altar, resume en sí siglos de historia y arte. En ella está la memoria histórica de la ciudad. ${ }^{8}$

La colegiata de Úbeda es el tercer templo en importancia de la provincia, después de las catedrales de Jaén y Baeza; su historia ha seguido un complicado camino y actualmente es: memoria histórica de la ciudad, en sus luces y en sus sombras o, si se quiere, en sus constantes, que no son ajenas a todo aquello que ha permitido que hoy celebremos su nombramiento de basílica menor por cumplir, entre otras condiciones, presentes en las exigencias del Decreto basilicae minoris:

[...] un cierto renombre en toda la diócesis, porque se ha construido y dedicado a Dios en ocasión de algún acontecimiento histórico y religioso en particular, o porque alguna imagen sagrada se venera allí de una manera especial; pudiéndose considerar también el valor histórico o la importancia de la iglesia y la dignidad de su arte.

Pues bien, sujeto fundamental en la historia de esta iglesia hubo de ser, junto a otras muchas realidades más conocidas y estudiadas, su capilla de música, la primera y principal de las que existieron en Úbeda.

\section{LA CAPILLA DE MÚSICA DE SANTA MARÍA EN LOS SIGLOS XVI, XVII Y XVIII}

Aunque sabemos del organista Pedro de Medina ya el 23 de julio de 1462, año en que el Concejo lo libra del pago de todos los pechos hasta cincuenta maravedíes, pensamos que el apogeo de la capilla de música de Santa María no va a desarrollarse plenamente hasta el siglo XVI. ${ }^{9}$ Así lo indican hechos tan significativos como son

\footnotetext{
8 Joaquín Montes Bardo, "Prólogo", en Almagro García, Santa María de los Reales Alcázares de Úbeda: Arqueología, Historia y Arte (Jaén: El Olivo, 2003), pp. 14-15.

9 Véase A.H.M.Ú., F.M., S.A.C., 1, s.f. Marín López, ¿¿Una historia imposible? Música y devoción en Úbeda durante el Antiguo Régimen", p. 146, apunta, sin señalar fuente, para finales
} 
la erección de un coro por esos mismos años, ocupando la nave central del templo, y los posteriores reglamentos y normas dictadas sobre su orden por distintos obispos. ${ }^{10}$ Ese es el dato de mayor antigüedad que conocemos sobre los organistas y, además, en un contexto documental que llegó a ser habitual para los músicos. Así, al menos, parece deducirse de una petición del maestro de capilla de la colegial, Francisco Monleón, junto con los músicos y ministriles de la misma, solicitando el 7 de abril de 1664 que se les liberara de las cargas concejiles, repartimientos de soldados y campaña que la ciudad tuviere, ya que asistían a todas las fiestas celebradas en Santa María y, muy especialmente, a las de la patrona, la Virgen de Guadalupe. ${ }^{11}$ De hecho, en los padrones de repartimiento consultados del año 1673 y de otros de finales del mismo siglo están libres de pechar: maestros de capilla, ministriles, músicos y sochantres. ${ }^{12}$

En lo que se refiere a la creación del coro arquitectónicamente hablando, creemos que se empieza a levantar a finales del siglo XV o al principio del XVI, atendiendo a una serie de testamentos que de él nos hablan. Tuvo cinco o seis capillas perimetrales, cuya construcción es anterior a la de la reja y sillería, y en un momento indeterminado se tapiaron hasta 1890; existían muestras de pintura mural. Las obras se realizaron por artífices como el maestro Bartolomé, Gutierre Gyerero, Juan de Reolid y Luis de Aguilar, al amparo del mecenazgo de los obispos don Francisco Mendoza (15381543) y don Pedro Pacheco (1545-1550); el recinto se coronaba con crestería gótica. ${ }^{13}$

Los datos anteriores al siglo XVIII que nos han llegado sobre la capilla de música son especialmente escasos y dispersos. Sabemos, por ejemplo, que era su maestro en 1643 Francisco del Mármol, año en que el 7 de enero se compromete a asistir a la fiesta del Santísimo para "[...] poner en perfeçión un coloquio o acto sacramental"; si los comisarios de la fiesta no se lo entregaren, el maestro lo haría o buscaría durante el mes de febrero.

del siglo XVI la existencia de “...al menos cuatro acólitos, un organista y quizá algunos ministriles, además del propio maestro de capilla".

${ }^{10}$ Almagro García, Santa María de los Reales Alcázares de Úbeda.

11 A.H.M.Ú., F.M., S.A.C., 21, fol. 52.

12 A.H.M.Ú., F.M., S.P.R., 28/17.

${ }^{13}$ Almagro García, Santa María de los Reales Alcázares de Úbeda.
Además, estos proporcionarían para cada muchacho "[...] un baguero de la tela que quisieren y un sombrero rojo, calças y çapatos", cobrando por todo cuarenta ducados..$^{14}$ Es decir, que al menos se nos informa de distintas circunstancias: la posibilidad de componer por el propio maestro, la existencia de seises, la realidad de contratarse para entidades o fiestas externas a la institución que mantiene la capilla de música y la disposición de vestimentas especiales como el denominado "baguero". Este término debe referirse a braguero como prenda que, además de otras acepciones, la usaban, según Covarruvias "los pregoneros, porque no se quebrasen, dando grandes vozes. Los comediantes, los cantores, los trompeteros, y los demás que tañían instrumentos de boca". ${ }^{15}$ Aunque aquí creemos que sólo hace referencia a la que cubría el vientre y las nalgas sobre las calzas, algo propio de la vestimenta del momento.

Por Marín López y Torres Navarrete conocemos a más maestros de esta capilla (véase Tabla 1), algunos de los cuales se corroboran por la documentación presentada por nosostros en el siguiente apartado de este trabajo: ${ }^{16}$

\begin{tabular}{|c|c|c|}
\hline Nombre & Año y origen & Año y destino \\
\hline $\begin{array}{l}\text { Juan Bautista } \\
\text { Coronada }\end{array}$ & $\begin{array}{c}\text { Después de } \\
1583\end{array}$ & Antes de 1604 \\
\hline $\begin{array}{l}\text { Francisco } \\
\text { Martínez de } \\
\text { Ávalos }\end{array}$ & En torno a 1605 & $\begin{array}{c}1618 \\
\text { ¿Catedral de } \\
\text { Guadix o Baza? }\end{array}$ \\
\hline $\begin{array}{c}\text { Juan Benítez de } \\
\text { Riscos }\end{array}$ & $\begin{array}{c}1617 \\
\text { Capilla de San } \\
\text { Andrés de Baeza }\end{array}$ & $\begin{array}{c}1624 \\
\text { Colegiata de } \\
\text { Antequera }\end{array}$ \\
\hline $\begin{array}{l}\text { Francisco } \\
\text { Monleón }\end{array}$ & Antes de 1664 & \\
\hline Juan de Navarro & $\begin{array}{c}1679 \\
\text { Catedral de } \\
\text { Córdoba }\end{array}$ & $\begin{array}{c}\text { Después de } \\
1681\end{array}$ \\
\hline Gregorio Navarro & 1760 & 1777 \\
\hline
\end{tabular}

${ }^{14}$ A.H.M.Ú., F.P.N., 124, fol. 16.

15 Sebastián de Covarrubias, Tesoro de la lengua castellana o española (Barcelona: Alta Fulla, 1611), fol. 150v.

16 Marín López, “Una historia imposible? Música y devoción en Úbeda" y, del mismo autor, "Úbeda", pp. 542-544; y Torres Navarrete, Historia de Úbeda en sus documentos. 


\begin{tabular}{|c|c|c|}
\hline Nombre & Año y origen & Año y destino \\
\hline $\begin{array}{c}\text { Francisco de } \\
\text { Paula González }\end{array}$ & $\begin{array}{c}\text { Después de } \\
1777\end{array}$ & $\begin{array}{c}\text { Después de } \\
1787^{17}\end{array}$ \\
\hline $\begin{array}{c}\text { Dionisio } \\
\text { Rodríguez } \\
\text { Lloveras }\end{array}$ & $\begin{array}{c}1798 \\
\text { Colegiata de El } \\
\text { Salvador de } \\
\text { Granada }\end{array}$ & $\begin{array}{c}1799 \\
\text { Colegiata de } \\
\text { Castellar }\end{array}$ \\
\hline
\end{tabular}

Tabla 1. Maestros de capilla de la colegiata de Santa María de los Reales Alcázares de Úbeda. Elaboración propia a partir de Marín López y Torres Navarrete.

Torres Navarrete ya nos habla de Francisco Martínez de Ávalos que, nacido en Úbeda hacia 1520, pronto "destacó por su pericia y dedicación en el difícil arte de componer, interpretar y dirigir" ${ }^{18}$ Formó parte del coro de la colegiata para ser después organista segundo, primero y maestro de capilla; con posterioridad, se traslada a la catedral de Guadix y, quizá, a la de Granada. Marín López también cita a un Francisco Martínez de Ávalos como maestro de capilla de El Salvador en torno a 1603 para pasar a la catedral de Baza en 1618 (fechas, en este caso, coincidentes con las apuntadas por Torres Navarrete) $;{ }^{19}$ por otra parte, este autor, como vemos, nos presenta al músico como nacido en 1520. Ante esta disparidad de fechas, debemos pensar en un doble error: el primero, el de la fecha de nacimiento y, el segundo, la afirmación de Marín López apuntando que era maestro de la capilla de El Salvador y no de Santa María, algo del todo imposible: en 1605 hemos documentado como maestro de la Sacra Capilla, no a Martínez de Ávalos, sino a Miguel Hidalgo, empadronado en la calle de los Molinos, parroquia de San Lorenzo. ${ }^{20}$

Por otra parte, del maestro Juan de Navarro, Marín López aporta una interesante correspondencia (concretamente seis cartas de los años 1679 a 1681) con Miguel de

${ }^{17}$ Consideramos que este dato no es correcto. Veremos cómo Francisco de Paula González sigue siendo maestro de capilla todavía al final del siglo XVIII. Puede verse lo recogido sobre los cabildos de 15 de octubre de 1596 y de 10 de junio de 1797 en el apartado siguiente. Posiblemente se trate simplemente de un error relacionado con la confusión de un número de la fecha: 1787 por 1897.

18 Torres Navarrete, Historia de Úbeda en sus documentos, p. 419.

19 Marín López, "Úbeda”, p. 543.

20 Véase A.H.M.Ú., F.M., S.P.R., 25/2.
Irízar, maestro de capilla de la catedral de Segovia, que proporciona interesantes detalles sobre la vida personal y sobre intercambios de composiciones, como algo que debió ser habitual:

Por un lado, Navarro manda a Irízar villancicos (en este contexto, debe entenderse tanto los pliegos impresos con las letras como las propias partituras musicales) que se habían interpretado en algunos centros andaluces, en particular, en las catedrales de Granada y Córdoba (de donde Navarro procedía y mantenía contactos). Este hecho indica que los músicos de Úbeda, o al menos algunos de ellos, formaban parte de las redes de contactos personales que operaban entre los músicos eclesiásticos. Además, Navaro también envía algunas obras propias: "para la Pascua de Resurreción remitiré dos o tres [villancicos] de Corpus" (carta 3), "remito a vuestra merced esos [villancicos] que holgare sean del agrado de vuestra merced" (carta 1). El hecho de que en el archivo de música de la Catedral de Segovia se conserve el villancico Ay cuando de tanta noche a 10 voces adscrito a Navarro parece, en efecto, apuntar a que se trata de una obra compuesta por el maestro de capilla ubetense y enviada a Irízar. ${ }^{21}$

Gracias a las actas capitulares de la colegial (las pocas pertenecientes al siglo XVII), conservadas en el Archivo de la Casa Ducal de Medinaceli en Sevilla, de las que ya hemos extraído el nombre de algunos de los maestros de capilla presentados, conocemos dos únicos datos más para el siglo XVII, por lo demás, muy habituales en el funcionamiento de las capillas de música: la concesión (cabildo de 15 de septiembre de 1696) de cuatro arrobas más de trigo anuales, tras la petición de aumento de renta que presenta el ministril Francisco Xabier para no verse obligado a abandonar Úbeda y marchar a Jaén, dejando la capilla de música; y la constancia (cabildo de 10 de mayo de 1698) de la profusa presencia de la capilla de música en funciones y entierros fuera de la colegiata para lo que se solicitaba permiso al canónigo tesorero.

Resulta interesante para el siglo XVII y, especialmente, para el XVIII la evidencia de contrataciones de músicos y de capillas de música de la ciudad al completo para celebraciones de todo tipo, tanto religiosas, generalmente asociadas a cofradías, como profanas. Las capillas contratadas son las de la Sacra Capilla de El Salvador y la de la colegiata de Santa María, pues la del Hospital de Santiago pronto,

\footnotetext{
${ }^{21}$ Marín López, ¿¿Una historia imposible? Música y devoción en Úbeda durante el Antiguo Régimen”, pp. 149 y 160-162.
} 
hacia la segunda mitad del XVII, entró en decadencia. Las contrataciones se hacen siempre con permiso de la entidad que las ampara o del mismo obispo para tocar no sólo en celebraciones desarrolladas en la ciudad, sino también en otros lugares de la provincia. Son numerosos los compromisos de la capilla de la colegial para desplazarse a lugares del arciprestazgo como Sabiote, Castellar, Torreperogil y Jódar. Ejemplificadora es, en en este sentido, la carta de 8 de marzo de 1691 por la que el obispo fray Juan Asensio pide al Concejo que dé permiso a los músicos de El Salvador para asistir a las funciones para las que fuesen reclamados. ${ }^{22}$

Pero hay más y diversas ocasiones en las que la música fue algo cotidiano, como parece deducirse de otros momentos recogidos en las actas capitulares, muy especialmente los relacionados con las proclamaciones reales, en las que junto a los actos de carácter religioso - con el protagonismo para la música sacra - adquieren importancia otros celebrados en la calle, en los que otro tipo de música está siempre presente. ${ }^{23}$ En las manifestaciones relacionadas con las proclamaciones reales comola tremolación del pendón, el lanzamiento de monedas al pueblo, las luminarias, las máscaras, los tablados, el repique de campanas, las cabalgatas, los carros triunfales, los toros y las mascaradas, los músicos cobran protagonismo. Así, a modo de ejemplo, a la proclamación de Luis I - que se celebró con luminarias, repique de campanas, cuadrillas, juramento de fidelidad, función religiosa con música y villancicosasistieron "los timbales, clarines, ministriles de las dos capillas de música con sus instrumentos aziendo una armonía mui acorde". ${ }^{24}$ Para la proclamación de Fernando VI era preciso traer clarines y timbaleros de Córdoba o Granada por 1.500 reales, mientras que a los músicos de las capillas de Úbeda se les dan 750 reales. ${ }^{25}$ En la proclamación de Carlos III, durante tres noches en la galería alta de las casas consistoriales "asistieron dos capillas de música con varios instrumentos que cantaron, diversas cantadas, y tocaron

\footnotetext{
22 A.H.M.Ú., F.M., S.A.C., 30, fol. 170.

${ }^{23}$ Para un estudio detallado sobre la música en las fiestas de proclamación real, véase María José de la Torre Molina, Música y ceremonial en las fiestas reales de proclamación de España e Hispanoamérica (1746-1814) (Granada: Universidad de Granada, 2004).

${ }^{24}$ A.H.M.U., F.M., S.A.C., 39, fols. 43 y ss., a 26 de marzo de 1724 .

${ }^{25}$ A.H.M.Ú., F.M., S.A.C., 49, fol. 76, a 28 de diciembre de 1746.
}

con universal concurso y alegría de todo el pueblo" ${ }^{26}$ Úbeda celebra el nacimiento de la princesa Carlota Joaquina y ordena se celebren "sonoros conciertos" por las capillas de música. ${ }^{27}$ En el presupuesto de gastos para la proclamación de Carlos IV (con un total de 76.300 reales) constan ochocientos "para gratificar las dos capillas de música que hai en esta ciudad que también deben según costumbre asistir a dicha funzión". ${ }^{28}$ Finalmente, ya en la proclamación de este rey, que vino preparándose a lo largo de varios meses de 1789 y que resulta ser la más extraordinaria que conocemos por los gastos, adornos y actos programados, se sirve según consta en el acta capitular de 6 de febrero de 1790:

[...] un espléndido, abundante y delicado refresco, con cena, y vaile que duró hasta las seis del siguiente día, a que por lo menos concurrieron más de seiscientas personas de ambos sexos, traiéndo a sus propias espensas la Música del Regimiento Provincial de Jaén, el que con el del Provincial de Guadix, la Maestranza de Granada, y las urbanas de Santa María y El Salvador compusieron la más deleitable y armoniosa horquesta. ${ }^{29}$

\section{LA CAPILLA DE MÚSICA DE SANTA MARÍA DE ÚBEDA EN LAS ACTAS CAPITULARES DEL SIGLO XVIII (1751-1759 / 1792-1798) ${ }^{30}$}

La presentación de todos los acuerdos - aproximadamente un centenar - relacionados con la capilla de música

${ }^{26}$ A.H.M.Ú., F.M., S.A.C., 52, fols. 178 y ss., a 11 de diciembre de 1759.

27 A.H.M.Ú., F.M., S.A.C., 54, fol. 67, a 23 de mayo de 1775.

28 A.H.M.Ú., F.M., S.A.C., 55, fols. 246 y ss., a 13 de marzo de 1789 .

${ }^{29}$ A.H.M.Ú., F.M., S.A.C., 55, fols. 325 y ss. La proclamación se realiza el 30 de septiembre de 1789. Finalmente, los gastos ascendieron a 70.721 reales, algo menos de lo presupuestado.

30 Estas actas se recogen en 21 libros o fascículos (según la organización de la copia digital del Archivo Ducal de Medinaceli sobre la que hemos trabajado) que abarcan las siguientes fechas y recogen más de un centenar de referencias relacionadas con la música y la capilla de música: $\mathbf{1}^{\mathbf{0}}$ : del 25 de agosto de 1684 al 25 de diciembre de $1686 ; \mathbf{2}^{\mathbf{0}}$ : del 2 de enero de 1689 al 16 de julio de 1689; $3^{\mathbf{0}}$ : del 20 de agosto al 28 de junio de 1696; $\mathbf{4}^{\mathbf{0}}$ : del 5 de junio al 18 de febrero de $1696 ; \mathbf{5}^{\circ}$ : Del 27 de febrero de 1696 al 2 de diciembre de $1699 ; \mathbf{6}^{\circ}$ : del 19 de septiembre de 1699 al 4 de febrero de $1702 ; 7^{\circ}$ : del 1 de abril de 1702 al 28 de noviembre de 1750 ; $\mathbf{8}^{\mathbf{o}}$ : del 12 de diciembre de 1750 al 7 de abril de $1753 ; \mathbf{9}^{\circ}$ : del 16 de abril de 1753 al 1 de febrero de $1755 ; \mathbf{1 0}^{\circ}$ : del 8 de febrero de 1755 al 18 de junio de $1757 ; \mathbf{1 1}^{\mathbf{0}}$ : del 22 de junio de 1757 al 19 de 
de la colegiata de Santa María de Úbeda en las actas capitulares del siglo XVIII conservadas en el Archivo Ducal de Medinaceli ilustra su régimen, funcionamiento, características, funciones y papel desempeñado, no sólo en la institución que la cobija, sino también en la vida musical de toda la ciudad y de su arciprestazgo. ${ }^{31}$ Gracias a esta documentación también se recupera el nombre de muchos de sus componentes, de sus circunstancias profesionales y personales, ampliando el listado conocido de maestros de capilla, cantores, ministriles y sochantres. Y lo hace de forma directa, con documentación de primera mano - hasta ahora desconocida - que podría además extrapolarse a momentos de la historia de la capilla huérfanos de documentación que, muy posiblemente, nos hablarían de aspectos conocidos para otras capillas de la ciudad, como la de la importante Sacra Capilla del Salvador del Mundo, organizada así en 1568: ${ }^{32}$

Ytem los cantores desta sancta iglesia, estarán obligados a cantar canto de órgano en la forma siguiente: las pascuas en las primeras bísperas y la fiesta del Salvador y de la Límpia Concepción cantarán tres psalmos es a saber el primero tercer y quinto de las bísperas y el Himno y la magnificat. En las fiestas en las que ay maytines excepto por los días de la octava del santísimo sacramento se dirán las bísperas a canto de órgano el primer psalmo y quinto y la Magnificat. Todos los días de fiesta y los domingos en que se suelen cantar se

abril de $1760 ; \mathbf{1 2}^{\mathbf{0}}$ : del 29 de mayo de 1760 al 20 de febrero de $1760 ; 1^{\circ}$ : del 18 de febrero de 1792 al 19 de enero de $1793 ; \mathbf{1 4}^{\mathbf{0}}$ : del 13 de febrero de 1793 al 18 de enero de1794; $\mathbf{1 5}^{\circ}$ : del 22 de enero de 1794 al 11 de diciembre de $1794 ; \mathbf{1 6}^{\circ}$ : del 13 de diciembre de 1794 al 3 de noviembre de $1795 ; \mathbf{1 7}^{\circ}$ : del 7 de noviembre de 1795 al 18 de julio de $179 ; \mathbf{1 8}^{\mathbf{0}}$ : del 6 de agosto de 1796 al 7 de julio de $1798 ; \mathbf{1 9}^{\circ}$ : del 14 de julio de 1798 al 9 de julio de 1831 ; $\mathbf{2 0}^{\mathbf{o}}$ : del 14 de julio de 1831 al 3 de junio de $1837 ; \mathbf{2 1}^{\mathbf{0}}$ : del 19 de noviembre de 1796 al 9 de diciembre de 1797 .

31 Véanse los acuerdos sobre música de las actas capitulares en los Apéndices 1 y 2, y los datos extraídos de las mismas, organizados por temas, en la Tabla 2.

${ }^{32}$ La sacra Capilla de El Salvador, magno proyecto de don Francisco de los Cobos, Secretario de Estado de Carlos V, se concibe como una ambiciosa aspiración de múltiples facetas: capilla privada, gozando como tal de sus propios y exclusivos estatutos aprobados por el papado; marcado carácter funerario; símbolo del poder personal y del rango social; incorporación de lo monástico con la creación de un convento para religiosos o religiosas, que finalmente no prosperó; e incorporación de lo académico, mediante el establecimiento de un Estudio General al cual su Santidad Paulo III en 1541 otorga todos los privilegios y prerrogativas concedidas e que se concedieren a Bolonia, París, Salamanca y Alcalá. cantará la missa mayor a canto de órgano y en los domingos de adviento septuag ${ }^{\text {ma }}$. y quaresma, credo y Motete. En la semana sancta, en la octava del santísimo sacramento cantar sea como se a acostumbrado hasta aquí también en las tinieblas y en los sábados. En los aniversarios se cantará motete, responso y lo demás que quieran cantar para alabanza de nro. Sr. y motivos particulares que para ello podrán ocurrir hazerlo an con toda liberalidad como siervos de nro. Señor lo cual dexamos a dispusición del Maestro de capilla y de los demás cantores como no se dexe de cantar los días aquí señalados y si por alguno o algunos faltare de malicia el capellán mayor o su sustituto o el cabildo, lo podrán multar en lo que justo fuere tiniendo atención a la fiesta que fuere y sigún la falta o nota fuere mayor o menor y también cantarán las demás veces que el capellán mayor les mandare.

Y también mandamos que el organista sea obligado a tañer dobles mayores y dobles y semidobles y los domingos acostumbrados los sábados y octavas mayores y guarde la orden que se tiene en tañer en la capilla real de Granada o en la iglesia mayor de Jaén o en otras cathedrales, y no tome licencias en los días que a de tañer, sino fuese dexando proveydo otro que supla por él como no se dexe de tañer los días aquí señalados.

Ytem por quanto los divinos officios se dizen y cantan con devoción y para que siempre se haga ansí quiero y es mi voluntad que destas doze capellanías se provean las cinco para cantores en esta manera que la una sea para un maestro de capilla muy abil y sufficiente en la música q. enseñe a los mozos de coro, y otra capellanía se provea en un contravajo y otra a un tenor y otra un tiple y otra a un contraalto que sean personas hábiles y de muy buenas vozes y porque al presente están proveydos tres en Maestro de capilla y en contravajo y en tenor, quiero y es mi voluntad que las dos capellanías primeras que vacaren se provean en un tiple y un contraalto porque la música que de pre $^{\text {te }}$. ay no falte y quando quiera que qualquiera destas probeydas en los cantores y Maestro vaccaren, se envien edictos a las iglesias cathedrales de Granada, Toledo, Jaén y Sevilla y a otras donde a el Capellán mayor le pareciere e venidos los que se oppusieren muestren su abilidad y examinándolos el capellán mayor con los cantores y de los que que se opusieren elija el capellán mayor con los cantores dos de los más áviles y de mejores vozes y costumbres puniendo al primero por primero y al sigundo por sigundo me los remitan a mí o al patrón que por el tiempo fuere para que yo elija el que quisiere, y quiero que estas cinco prebendas estén señaladas como tengo dicho para maestro y cantores porque cada uno y quando que algunas dellas vacare no se pueda proveer a otra persona alguna si no fuere a cantor como dicho tengo y por el orden que está dicho. ${ }^{33}$

\footnotetext{
33 A.H.M.Ú., 6238.
} 
Consideramos metodológicamente clarificador presentar de forma resumida y por temas en la siguiente Tabla 2 los datos procedentes de las actas capitulares de la colegiata de Santa María de Úbeda que se conservan en el Archivo Ducal de Medinaceli (se distinguen porque la fecha aparece completa), junto a algunos otros procedentes de distintas fuentes documentales y bibliográficas:

\begin{tabular}{|c|c|}
\hline $\begin{array}{l}\text { MAESTROS DE } \\
\text { CAPILLA }\end{array}$ & $\begin{array}{l}\text { - JUAN BAUTISTA CORONADA (después de 1583-antes de 1604). } \\
\text { - FRANCISCO MARTÍNEZ DE ÁVALOS (antes de 1603-después de 1618). } \\
\text { - JUAN BENÍTEZ DE RISCOS (1617-1624). } \\
\text { - FRANCISCO DEL MÁRMOL (1643-...). } \\
\text { - FRANCISO MONLEÓN (antes de 1664-...). } \\
\text { - JUAN NAVARRO (1679- después de 1681). } \\
\text { - GREGORIO NAVARRO (1760-1777). } \\
\text { - FRANCISCO DE PAULA GONZÁLEZ (después de 1777-después de 1787; } \\
\text { 13/07/1793; 22/12/1794; 15/10/1796; 10/06/1797; 22/08/1797). } \\
\text { - DIONISIO RODRÍGUEZ LLOVERAS (1798-1799; 22/08/1797; 19/09/1787; } \\
\text { 23/12/1797; 20/10/1798). }\end{array}$ \\
\hline $\begin{array}{l}\text { OBLIGACIONES } \\
\text { DEL MAESTRO DE } \\
\text { CAPILLA }\end{array}$ & - DIONISIO RODRÍGUEZ LLOVERAS (22/08/1797). \\
\hline INSTRUMENTOS & $\begin{array}{l}\text { - ARPA }(06 / 11 / 1751) . \\
\text { - BAJO (14/03/1757; 15/01/1755; 15/03/1757; 17/05/1793; 18/01/1794). } \\
\text { - CHIRIMÍA (17/05/1793). } \\
\text { - ÓRGANO (12/01/1793; 12/11/1796). } \\
\text { - TROMPA }(17 / 05 / 1793 ; 18 / 01 / 1794 ; 19 / 09 / 1797 ; 21 / 10 / 1797) . \\
\text { - VIOLA }(17 / 05 / 1793) . \\
\text { - VIOLÍN }(16 / 12 / 1797 ; 23 / 12 / 1796 ; 07 / 01 / 1797 / 21 / 10 / 1797) . \\
\text { - VIOLÓN }(17 / 05 / 1793) .\end{array}$ \\
\hline ARPISTAS & GASPAR (sic), EN SUSTITUCION DE DIEGO ROA (6/11/1751). \\
\hline BAJONISTA & $\begin{array}{l}\text { - FRANCISCO DE MOLINA (14/03/1757; 15/01/1755; 15/03/1757). } \\
\text { - FRANCISCO SORIA }(18 / 01 / 1794 ; 23 / 12 / 1796) .\end{array}$ \\
\hline ORGANISTAS & $\begin{array}{l}\text { - PEDRO DE MEDINA, } 1462 . \\
\text { - FRANCISCO MONLEÓN, } 1664 . \\
\text { - JOSEPH VICO (12/01/1793; 02/11/1796). } \\
\text { - JUAN JOSÉ DE LOS SANTOS, APRENDIZ (12/11/1796). }\end{array}$ \\
\hline VIOLINISTA & $\begin{array}{l}\text { - FRANCISCO TORAL (23/12/1796). } \\
\text { - MILLÁN SÁNCHEZ (07/01/1797). } \\
\text { - JUAN JOSÉ DE LOS SANTOS (16/12/1797; 23/12/1797). }\end{array}$ \\
\hline SALMISTAS & $\begin{array}{l}\text { - AGUSTÍN CLIMENT (1794). } \\
\text { - JULIÁN GARCÍA (1791-1795). } \\
\text { - BERNARDO DE VARGAS (16/06/1792). } \\
\text { - MILLÁN SÁNCHEZ (15/12/1792; 22/12/1794; 01/10/1796). } \\
\text { - JULIÁN GARCÍA }(16 / 03 / 1793 ; 18 / 01 / 1794 ; 22 / 12 / 1794 ; 06 / 06 / 1795 ; 12 / 12 / 1795 ; \\
\text { 23/12/1786). } \\
\text { - MANUEL DE RAYA (16/03/1793; 18/01/1794; 22/12/1794; 01/06/1797). } \\
\text { - LUIS DE VARGAS }(23 / 12 / 1797) .\end{array}$ \\
\hline
\end{tabular}




\begin{tabular}{|c|c|}
\hline SOCHANTRES & $\begin{aligned} \text { - BARTOLOMÉ DE ALMAGRO (18/05/1754). } \\
\text { - SEBASTIÁN DE CONTRERAS, } 2^{\circ} \text { SOCHANTRE (14/03/1755). } \\
\text { - JOSÉ FELIPE DE GUZMÁN (20/11/1757; 12/03/1759). } \\
\text { - BERNARDO ANTONIO DE GUZMÁN, 2º SOCHANTRE (11/10/1757; 20/11/1757). } \\
\text { - CRISTÓBAL GÓMEZ (31/01/1759). } \\
\text { - JOSÉ VICO (12/01/1793). } \\
\text { - JULIÁN DE RUS (19/01/1793; 06/04/1793; 08/06/1793; 19/06/1793; 11/10/1794; } \\
\text { 18/10/1794; 03/06/1797; 10/02/1798). } \\
\text { - FRANCISCO GÓMEZ, 2 }{ }^{\circ} \text { SOCHANTRE (19/06/1793). } \\
\text { - AGUSTÍN CLIMENT (20/12/1794; 01/10/1796; 12/11/1796). } \\
\text { - MANUEL DE RAYA, 2 SOCHANTRE }(23 / 12 / 1797 ; 01 / 07 / 1797 ; 23 / 12 / 1797 ; \\
\text { 23/12/1797). }\end{aligned}$ \\
\hline TENORES & LUIS PÉREZ (24/03/1792). \\
\hline CONTRALTOS & $\begin{array}{l}\text { - FRANCISCO JAVIER DE SILVA Y PRÓSPERO, DE PORTUGAL (14/04/1792; } \\
\text { 07/12/1792). } \\
\text { - MATEO GÓMEZ (18/01/1794; 22/12/1794; 19/12/1795). } \\
\text { - ANTONIO LÓPEZ, CAPELLÁN DE CORO (20/05/1797). } \\
\text { - PEDRO VALENZUELA MOYAR O MOYA (02/09/1797; 04/11/1797; 10/02/1798). } \\
\text { - JOSÉ DE HONRUBIA (21/10/1797). } \\
\text { - JUAN DE LA TORRE (4/11/1797). }\end{array}$ \\
\hline $\begin{array}{c}\text { MÚSICOS Y } \\
\text { MÚSICOS DE VOZ }\end{array}$ & $\begin{aligned} \text { - LUIS DE ARJONA (20/01/1753). } \\
\text { - LORENZO DE OREA, HIJO DEL BAJONISTA FRANCISCO MOLINA (14/03/1755; } \\
\text { 15/01/1755). } \\
\text { - LUIS DE TAXONA (14/03/1755). } \\
\text { - MILLÁN SÁNCHEZ }(07 / 12 / 1792 ; 15 / 12 / 1792) . \\
\text { - MATEO GÓMEZ }(15 / 12 / 1792) . \\
\text { - FRANCISCO TORAL }(13 / 04 / 1793 ; 04 / 05 / 1793 ; 10 / 05 / 1794) . \\
\text { - FRANCISCO DE SORIA, TAMBIÉN SACRISTÁN (17/05/1793; 18/01/1794). } \\
\text { - MANUEL DE RAYA (18/01/1794; 01/10/1796; 23/12/1796). } \\
\text { - FRANCISCO PAREDES, OFICIAL AMANUENSE DE LA CONTADURÍA } \\
\text { (12/04/1794). } \\
\text { - JULIÁN GARCÍA }(16 / 03 / 1793 ; 18 / 01 / 1794 ; / 22 / 12 / 1794 ; 06 / 06 / 1795 ; 12 / 12 / 1795) . \\
\text { - PEDRO GARZÓN }(02 / 09 / 1797 ; 19 / 09 / 1797 ; 04 / 11 / 1797) . \\
\text { - JOSÉ DE HONRUBIA }(31 / 10 / 1797) .\end{aligned}$ \\
\hline TIPOS DE VOCES & $\begin{array}{l}\text { - CONTRALTO (14/04/1792; 21/10/1797). } \\
\text { - TENOR }(24 / 03 / 1792) .\end{array}$ \\
\hline SEISES & $\begin{array}{l}\text { - JULIÁN GARCÍA (16/03/1793). } \\
\text { - MANUEL DE RAYA (16/03/1793). }\end{array}$ \\
\hline $\begin{array}{c}\text { AUMENTOS DE } \\
\text { SALARIO }\end{array}$ & $\begin{array}{l}\text { - GENERALMENTE SE SOLICITAN EN EL MES DE DICIEMBRE. EN EL } \\
\text { PERIODO ESTUDIADO. GENERALMENTE SE ACCEDE A LAS PETICIONES } \\
\text { BIEN EN LA REMUNERACIÓN DINERARIA O EN LA DE TRIGO. } \\
\text { - MEMORIAL DE MATEO GÓMEZ, MÚSICO DE VOZ DE LA CAPILLA DE } \\
\text { MÚSICA SOLICITANDO UN AUMENTO DE RENTA SOBRE LOS VEINTISÉIS } \\
\text { DUCADOS ANUALES QUE TENÍA. SE ACUERDA CONCEDERLE } 20 \text { DUCADOS } \\
\text { ANUALES Y CUATRO FANEGAS DE TRIGO }(15 / 12 / 1792) .\end{array}$ \\
\hline
\end{tabular}




\begin{tabular}{|c|c|}
\hline $\begin{array}{l}\text { AUMENTOS DE } \\
\text { SALARIO } \\
\text { (continuación) }\end{array}$ & 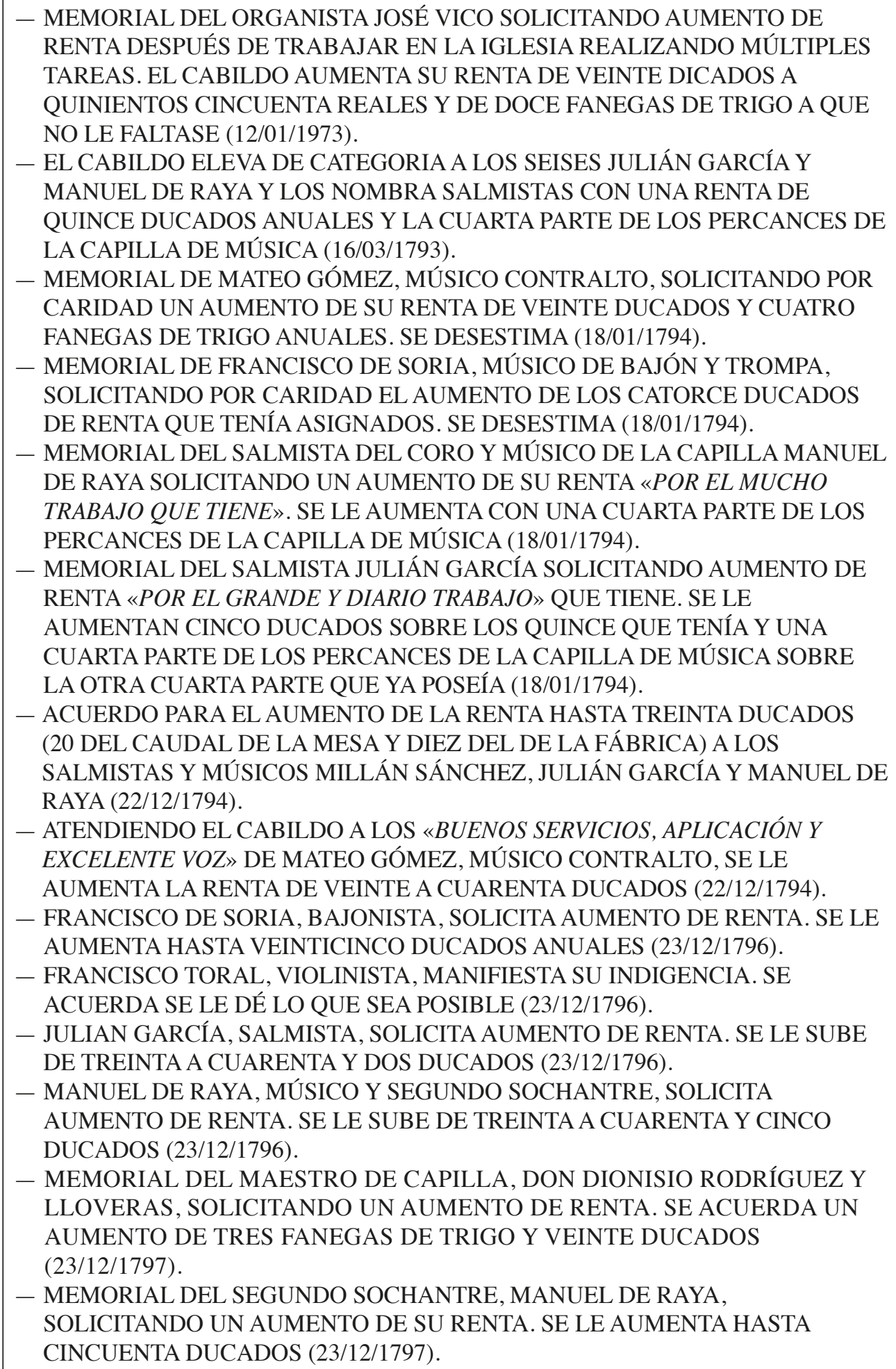 \\
\hline
\end{tabular}




\begin{tabular}{|c|c|}
\hline $\begin{array}{c}\text { LICENCIA PARA } \\
\text { OPOSITAR }\end{array}$ & $\begin{aligned} \text { - DIEGO DE AGUILAR, MAESTRO DE CAPILLA DEL HOSPITAL DE SANTIAGO } \\
\text { CUBRE ESTA PLAZA EN EL AÑO } 1568 . \\
\text { - MEMORIAL DEL BAJONISTA FRANCISCO DE MOLINA PIDIENDO LICENCIA } \\
\text { PARA IR A GUADIX A OPOSITAR PARA OPOSITAR A LA PLAZA DE } \\
\text { BAJONISTA. EL CABILDO LE DA LIDENCIA POR EL TIEMPO QUE } \\
\text { NECEIRARA (05/01/1757). } \\
\text { - MEMORIAL DEL SOCHANTRE PIDIENDO LICENCIA PARA OPOSITAR LA } \\
\text { PLAZA DE GUADIX. EL CABILDO LE DA LIDENCIA HASTA LA VÍSPERA DE } \\
\text { DOMINGO DE RAMOS (05/01/1757). } \\
\text { - MEMORIAL DEL SALMISTA BERNARDO DE VARGAS PIDIENDO LICENCIA } \\
\text { PARA OPOSITAR A UNA PLAZA DE DAVIDAZGO (SALMISTA) VACANTE EN } \\
\text { LA CATEDRAL DE BAEZA (07/12/1792). }\end{aligned}$ \\
\hline $\begin{array}{c}\text { ASIGNACIÓN, } \\
\text { ADMISIÓN, } \\
\text { CONTRATACIONES } \\
\text { DIRECTAS Y } \\
\text { EDICTOS PARA } \\
\text { CUBRIR PLAZAS } \\
\text { VACANTES }\end{array}$ & 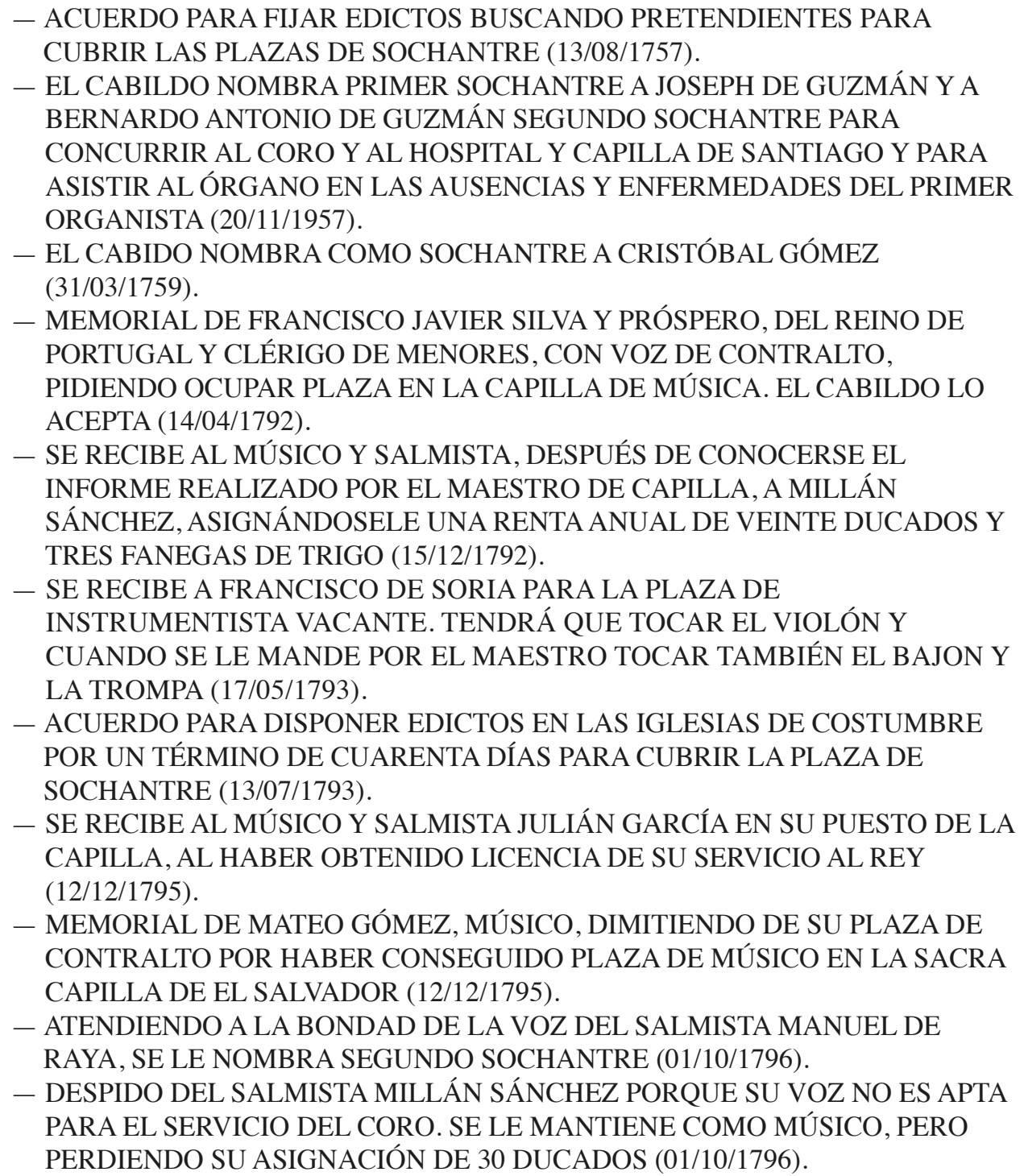 \\
\hline
\end{tabular}




\begin{tabular}{|c|c|}
\hline $\begin{array}{c}\text { ASIGNACIÓN, } \\
\text { ADMISIÓN, } \\
\text { CONTRATACIONES } \\
\text { DIRECTAS Y } \\
\text { EDICTOS PARA } \\
\text { CUBRIR PLAZAS } \\
\text { VACANTES } \\
\text { (continuación) }\end{array}$ & $\begin{array}{l}\text { - MEMORIAL DEL MAESTRO DE CAPILLA Y PRESBÍTERO DON } \\
\text { FRANCISCO DE PAULA GONZALEZ INFORMANDO DE QUE HA } \\
\text { OBTENIDO UNA CAPELLANÍA EN LA SACRA CAPILLA DEL SALVADOR, } \\
\text { PERO QUE ES SU INTENCIÓN CONTINUAR SIENDO MAESTRO DE } \\
\text { CAPILLA, EL CABILDO, ATENDIENDO A LOS MUCHOS MÉRITOS } \\
\text { DEMOSTRADOS EN LOS DIECISEIS AÑOS Y MEDIO QUE LLEVA } \\
\text { EJERCIENDO DE MAESTRO DE CAPILLA, ACCEDE A MANTENERLO EN } \\
\text { EL PUESTO (15/10/1796 } \\
\text { - POR DIMISIÓN DE DON FRANCISCO DE PAULA GONZÁLEZ, EL CABILDO, } \\
\text { PROCEDE A DAR A CONOCER UN MEMORIAL DE DON DIONISIO } \\
\text { RODRÍGUEZ Y LLOVERAS, PROCEDENTE DE EL SALVADOR DE GRANADA, } \\
\text { EN EL QUE SOLICITA LA PLAZA DE MAESTRO DE CAPILLA CON LA } \\
\text { OBLIGACIÓN DE COMPONER LAS FESTIVIDADES DEL CORPUS Y NAVIDAD } \\
\text { (22/08/1797). } \\
\text { - SE RECIBE COMO MAESTRO DE CAPILLA A DON DIONISIO RODRÍGUEZ } \\
\text { LLOVERAS (22/08/1797). }\end{array}$ \\
\hline $\begin{array}{c}\text { EXAMENES Y } \\
\text { SOLICITUDES PARA } \\
\text { CUBRIR PLAZAS } \\
\text { VACANTES }\end{array}$ & $\begin{array}{l}\text { - MARCO DEL CASTELLAR (1573): SE EXAMINA ANTE UN TRIBUNAL PARA } \\
\text { CONSEGUIR LA MAESTRÍA EN EL OFICIO DE DANZAR Y TOCAR. } \\
\text { - MEMORIAL DE MILLÁN SÁNCHEZ SOLICITANDOSE LE RECIBA PARA UNA } \\
\text { DE LAS PLAZAS DE MÚSICO VACANTES EN LA CAPILLA. EL CABILDO } \\
\text { ACUERDA QUE EL MAESTRO DE CAPILLA INFORME SOBRE LA } \\
\text { HABILIDAD DEL SUPLICANTE PARA DETERMINAR LO QUE TENGA } \\
\text { CONVENIENTE EL CABILDO (07/12/1792). } \\
\text { - MEMORIAL DE DON AGUSTÍN CLIMENT, NATURAL DE LA VILLA DE } \\
\text { BENIGANÍM, ARZOBISPADO DE VALENCIA, SALMISTA DE LA CATEDRAL } \\
\text { DE ORIHUELA, SOLICITANDO LA PLAZA DE SOCHANTRE (20/12/1794). } \\
\text { - VISTO EL INFORME EMITIDO POR DON FRANCISCO DE PAULA GONZÁLEZ, } \\
\text { MAESTRO DE CAPILLA, SOBRE LA SUFICIENCIA DE DON AGUSTÍN } \\
\text { CLIMENT, SE LE RECIBE COMO SOCHANTRE (22/12/1794). } \\
\text { - MEMORIALES DE DON PEDRO GARZÓN, MÚSICO QUE FÚ DE LA } \\
\text { CAPILLA, Y DE DON PEDRO VALENZUELA Y MOYAR, MÚSICO CON VOZ DE } \\
\text { CONTRALTO, OPTANDO A UNA ÚNICA PLAZA VACANTE. SE ADMITE A LOS } \\
\text { DOS CON UNA RENTA DE VEINTE DUCADOS Y OCHO FANEGAS DE TRIGO } \\
\text { (02/09/1797). } \\
\text { MEMORIAL DE JOSÉ DE HONRUBIA, MUSICO CON VOZ DE CONTRALTO E } \\
\text { INSTRUMENTISTA DE VIOLÍN Y TROMPA, SOLICITANDO SER ADMITIDO } \\
\text { EN LA CAPILLA DE MÚSICA (21/10/1797). } \\
\text { - SE RECIBE COMO MÚSICO A JOSÉ DE HONRUBIA CON LAS CONDICIONES } \\
\text { HABITUALES (31/10/1797). } \\
\text { - SOLICITUD DE LOS MÚSICOS DON PEDRO GARZÓN Y DON PEDRO } \\
\text { VALENZUELA PARA QUE SE LES APLIQUE POR MITAD LA PLAZA VACANTE } \\
\text { POR MUERTE DEL CONTRALTO JUAN DE LA TORRE. SE CONCEDE A } \\
\text { PARTIR DE ENERO PRÓXIMO (04/11/1797). } \\
\text { - SOLICITUD DE JUAN JOSÉ DE LOS SANTOS PARA OCUPAR PLAZA DE } \\
\text { SEGUNDO VIOLINISTA POR HABERSE AUSENTADO SIN LICENCIA JOSÉ DE } \\
\text { HONRUBIA, TITULAR DE LA PLAZA (16/12/1797; 23/12/1797). }\end{array}$ \\
\hline
\end{tabular}




\begin{tabular}{|c|c|}
\hline $\begin{array}{l}\text { MUI } \\
\text { INAS }\end{array}$ & $\begin{aligned} \text { — ACUERDO PARA QUE EL SECRETARIO ESCRIBA A FRANCISCO DE SILVA Y } \\
\text { PÓSPERO, MÚSICO DE VOZ DE LA CAPILLA, AMONESTÁNDOLE POR } \\
\text { FALTAS DE ASISTENCIA AL CORO. EL CABILDO ACUERDA QUE SE LE SIGA } \\
\text { DANDO LA RENTA HASTA FINAL DE AÑO (07/12/1792). } \\
\text { — EL CABILDO MANDA QUE SE OBSERVE Y CUMPLA DE LA FALTA DE } \\
\text { ASISTENCIA DE ALGUNOS MIEMBROS DE LA CAPILLA DE MÚSICA SIN } \\
\text { SOLICITAR LICENCIA POR ENFERMEDAD O VIAJE (19/01/1793). } \\
\text { - MEMORIAL DEL MÚSICO FRANCISCO TORAL SOBRE LA MULTA DE DIEZ } \\
\text { REALES IMPUESTA POR LA INASISTENCIA A LA COMUNIÓN GENERAL DEL } \\
\text { JUEVES SANTO (10/05/1794). }\end{aligned}$ \\
\hline $\begin{array}{l}\text { CAPELLANES } \\
\text { MENORES }\end{array}$ & $\begin{array}{l}\text { - MEMORIAL DE DON JOSÉ CLIMENT SOLICITANDO PERMISO PARA } \\
\text { ENTRAR EN EL CORO, MANIFESTANDO ALGUNOS PRINCIPIOS DE VOZ Y } \\
\text { ESTAR ESTUDIANDO CANTO GREGORIANO. SE LE RECIBE Y SE LE } \\
\text { NOMBRA CAPELLÁN DE MENORES (17/01/1795). }\end{array}$ \\
\hline $\begin{array}{c}\text { SANCIONES POR } \\
\text { COMPORTAMIENTO }\end{array}$ & $\begin{aligned} \text { — } & \text { SE SUSPENDE DE RENTA Y OFICIO POR DOS MESES AL MÚSICO } \\
& \text { FRANCISCO TORAL POR «PUNTO QUE NO CONVIENE EXPRESAR». DE } \\
& \text { REPETIRSE SERÍA DESPEDIDO (06/04/1793). } \\
\text { - } & \text { MEMORIAL DE FRANCISCO TORAL SOLICITANDO LE SEA LEVANTADA LA } \\
& \text { SANCIÓN IMPUESTA. EL CABILDO LA RATIFICA EN UN MES (13/04/1793). } \\
\text { - } & \text { ACUERDO PARA QUE EL TESORERO «HAGA COMPARECER ANTE SÍ A JOSÉ } \\
& \text { DE ROJAS A QUIEN DARÁ UNA FUERTE Y RÍGIDA REPRESIÓN SOBRE } \\
& \text { ALGUNAS FALTAS DE RESPETO QUE HA TENIDO EN LA IGLESIA Y VARIAS } \\
& \text { PERTURBACIONES QUE OCASIONA EN LA CAPILLA DE MUUSICA» } \\
& (13 / 04 / 1793) . \\
- & \text { EXPULSIÓN DEL VIOLINISTA MILLÁN SÁNCHEZ POR NO ENMENDARSE EN } \\
& \text { «SU SINIESTRO MODO DE PROCEDER» INCLUSO DESPUÉS DE SER } \\
& \text { REPRENDIDO, AMONESTADO Y MULTADO (07/01/1797). }\end{aligned}$ \\
\hline $\begin{array}{r}\mathrm{O} \\
\text { INFORN } \\
\text { TEMAS }\end{array}$ & $\begin{array}{l}\text { EN 1573, DON FRANCISCO DELGADO REDACTA UNOS NUEVOS ESTATUTOS QUE } \\
\text { REGIRÁN LA CAPILLA DE MÚSICA LA COLEGIAL DE SANTA MARÍA DE LOS } \\
\text { REALES ALCÁZARES. EL OBISPO DELGADO AÑADIÓ NUEVAS NORMAS EN } 1586 .\end{array}$ \\
\hline $\begin{array}{l}\text { NOMBRA } \\
\text { DE EMI }\end{array}$ & $\begin{aligned} \text { - } & \text { ANTE LA FALTA DE SOCHANTRE Y LA NO PRESENTACIÓN DE } \\
& \text { CANDIDATOS A LA PLAZA, SE ACUERDA PROPONER A DON JULIÁN RUS, } \\
& \text { SOCHANTRE JUBILADO, LA POSIBILIDAD DE ENTRAR EN EL CORO, SI LA } \\
& \text { SALUD SE LO PERMITIERE (11/10/1794). } \\
\text { - } & \text { EL SOCHANTRE JUBILADO DON JULIÁN DE RUS DECLINA LA PETICIÓN DE } \\
& \text { ASISTIR AL CORO ALEGANDO NO ESTAR DE ÁNIMO (18/10/1794). }\end{aligned}$ \\
\hline JUBILACIONES & $\begin{aligned} \text { — MEMORIAL DEL SOCHANTRE DON JULIÁN DE RUS SOLICITANDO SE } \\
\text { ATIENDA LA PETICIÓN DE JUBILACIÓN QUE TENÍA HECHA EN EL CABILDO } \\
\text { DE } 19 \text { DE ENERO. EL CABILDO RATIFICA LO DICHO EN LA REUNIÓN DE } \\
\text { ENERO Y SE CONCEDE OCHO DÍAS DE TÉRMINO (CABILDO DE 08/06/1793). } \\
\text { - } \text { MEMORIAL DEL SOCHANTRE DON JULIÁN DE RUS ALEGANDO } \\
\text { NUEVAMENTE DETERMINADOS MÉRITOS Y SOLICITANDO NUEVAMENTE } \\
\text { SE LE ASIGNE UNA PENSIÓN DE JUBILACIÓN (19/06/1793). } \\
\text { - ACUERDO, POR EL QUE SE CONCEDE AL SOCHANTRE DON JULIÁN DE RUS } \\
\text { EN ATENCIÓN A SUS MÉRITOS LA JUBILACIÓN. SE LE CONCEDE UNA } \\
\text { RENTA DE CUARENTA DUCADOS ANUALES Y PERPETUOS (19/06/1793). }\end{aligned}$ \\
\hline
\end{tabular}




\begin{tabular}{|c|c|}
\hline $\begin{array}{c}\text { CONSULTAS AL } \\
\text { OBISPADO }\end{array}$ & $\begin{array}{l}\text { EN 1691: EL OBISPO, FAY JUAN ASENSIO PIDE AL CONCEJO SE DÉ PERMISO A } \\
\text { LOS MUUSICOS DEL SALVADOR PARA ASISTIR A LAS FUNCIONES QUE LE } \\
\text { FUESE RECLAMADO. }\end{array}$ \\
\hline $\begin{array}{l}\text { LIBERACIÓN DE } \\
\text { CARGAS } \\
\text { CONCEJILES }\end{array}$ & $\begin{array}{l}\text { EN 1664: EL ORGANISTA DE LA CAPILLA COLEGIAL, FRANCISCO MONLEÓN } \\
\text { JUNTO CON LOS MÚSICOS Y MINISTRILES PIDEN AL CONCEJO QUE SE LES } \\
\text { LIBERE DE SUS CARGAS CONCEJILES, YA QUE ASISTÍAN A TODAS LAS } \\
\text { FIESTAS EN SANTA MARÍA Y MUY ESPECIALMENTE A LAS DE LA PATRONA, } \\
\text { LA VIRGEN DE GUADALUPE. }\end{array}$ \\
\hline $\begin{array}{l}\text { SALIDAS DE LA } \\
\text { CAPILLA A OTROS } \\
\text { LUGARES Y } \\
\text { CONTRATACIÓN DE } \\
\text { LAS MISMAS POR } \\
\text { LAS COFRADÍAS }\end{array}$ & $\begin{array}{l}\text { - ACUERDO, PARA RECORDAR QUE LA CAPILLA DE MÚSICA DEBE PEDIR } \\
\text { LICENCIA PARA SALIR FUERA DE ÚBEDA A SERVIR LOS PERCANCES QUE } \\
\text { LES OCURRAN EN OTROS PUEBLOS (11/10/1794). } \\
\text { - INFORMACIÓN DEL TESORERO SOBRE LA SOLICITUD DE LICENCIA DE LA } \\
\text { CAPILLA DE MÚSICA PARA IR A TORREPEROGIL (JUNTA DE 14/05/1796). } \\
\text { — INFORMACIÓN DEL TESORERO SOBRE LA SOLICITUD DE LICENCIA DE LA } \\
\text { CAPILLA DE MÚSICA PARA IR A TOCAR A LA FIESTA DE SAN GREGORIO } \\
\text { EN SABIOTE (JUNTA DE 14/05/1796). } \\
\text { - EL TESORERO DA CUENTA DE LA SOLICITUD DE LA CAPILLA DE MÚSICA } \\
\text { PARA SALIR A LA FIESTA DE SABIOTE A CELEBRAR EL DÍA SIGUIENTE } \\
\text { (13/05/1797). } \\
\text { - SOBRE LA PRESENCIA DE LA CAPILLA DE MÚSICA EN JÓDAR PARA LA } \\
\text { FIESTA DEL CRISTO DE LA MISERICORDIA, EL CABILDO FACULTA AL } \\
\text { TESORERO PARA QUE PROCURE DICHA PRESENCIA (22/08/1797). } \\
\text { - PERMISO PARA QUE LA CAPILLA DE MUSICA ACUDA A SOLEMNIZAR LA } \\
\text { FIESTA DE LA HERMANDAD DE NUESTRA SEÑORA DEL ROSARIO (JUNTA } \\
\text { DE 30/09/1797). } \\
\text { - SE DA CUENTA POR EL SEÑOR TESORERO QUE LA CAPILLA DE MÚSICA } \\
\text { ASISTIRÁ EN EL MES DE SEPTIEMBRE A FIESTAS EN JÓDAR, } \\
\text { TORREPEROGIL Y SABIOTE, VILLAS DEL ARCIPRESTAZGO DANDO } \\
\text { PERMISO EL CABILDO (18/08/1798). }\end{array}$ \\
\hline $\begin{array}{l}\text { ASISTENCIA A } \\
\text { FIESTAS DE } \\
\text { COFRADÍAS EN } \\
\text { DOCUMENTACIÓN } \\
\text { DEL ARCHIVO } \\
\text { MUNICIPAL }\end{array}$ & $\begin{array}{l}\text { - CELEBRACIONES ASOCIADAS A LAS COFRADÍAS CON SEDE EN } \\
\text { PARROQUIAS: } \\
\text { - LAS DE LA PATRONA, VIRGEN DE GUADALUPE. } \\
\text { - LAS DE LA CANDELARIA. } \\
\text { - LAS DE LA VIRDEN DEL ROSARIO. } \\
\text { - LAS DE NUESTRA SRA. DE LA MERDED. } \\
\text { - LAS DE LA VIRGEN DE LA CABEZA. } \\
\text { - LAS DEL SANTÍSIMO SACRAMENTO. } \\
\text { - EN HONOR A SAN JUAN DE DIOS (CONVENTO SAN MIGUEL, 1676). } \\
\text { - FIESTA DE SAN SEVERIANO (1680). }\end{array}$ \\
\hline VILLANCICOS & $\begin{array}{l}\text { - EL HECHO DE QUE EN EL ARCHIVO DE MÚSICA DE LA CATEDRAL DE } \\
\text { SEGOVIA SE CONSERVE EL VILLANCICO AY CUANDO DE TANTA NOCHE A } \\
\text { DIEZ VOCES, ADSCRITO A NAVARRO PARECE APUNTAR A QUE SE TRATA } \\
\text { DE UNA OBRA MAESTRA COMPUESTA POR EL MAESTRO DE CAPILLA } \\
\text { UBETENSE Y ENVIADA A MIGUEL ÍRÍZAR, MAESTRO DE CAPILLA DE LA } \\
\text { CATEDRAL DE SEGOVIA (SEIS CARTAS ENTRE JUAN NAVARRO Y MIGUEL } \\
\text { IRÍZAR, 1679-1681). }\end{array}$ \\
\hline
\end{tabular}




\begin{tabular}{|c|c|}
\hline $\begin{array}{l}\text { VILLANCICOS } \\
\text { (continuación) }\end{array}$ & $\begin{array}{l}\text { - SE CITAN POR EL MAESTRO DE CAPILLA FRANCISCO DE PAULA } \\
\text { GONZÁLEZ (15/10/1796). } \\
\text { - ORDEN DE MANDARLOS A LA IMPRENTA (12/11/1796). }\end{array}$ \\
\hline $\begin{array}{l}\text { IMPRESIÓN DE } \\
\text { PARTITURAS }\end{array}$ & $\begin{array}{l}\text { - UNA REALIZADA POR ORDEN DEL CABILDO EL MAESTRO DE CAPILLA } \\
\text { DIONISIO RODRÍGUEZ LLOVERAS. SE LE ENTREGA UNA RESMA DE PAPEL. } \\
\text { - EL TESORERO INFORMA DE COMO LAS LETRAS DE LOS VILLANCICOS } \\
\text { QUE SE HAN DE CANTAR EN LOS MAITINES DE NAVIDAD, SE HAN DE } \\
\text { MANDAR A LA IMPRENTA }(12 / 11 / 1796) .\end{array}$ \\
\hline $\begin{array}{l}\text { LUGARES QUE SE } \\
\text { CITAN FUERA DE } \\
\text { ÚBEDA }\end{array}$ & $\begin{array}{l}\text { - BAEZA }(06 / 11 / 1751) \\
\text { - GUADIX }(05 / 03 / 1757 ; 12 / 03 / 1757) \\
\text { - GRANADA }(11 / 10 / 1757) \\
\text { - PORTUGAL (14/04/1792). } \\
\text { - BAEZA (16/06/1792). } \\
\text { - BENIGANIM, ARZOBISPADO DE VALENCIA (20/12/1794). } \\
\text { - TORREPEROGIL }(14 / 05 / 1796 ; 18 / 08 / 1798) . \\
\text { - SABIOTE }(14 / 05 / 1796 ; 13 / 05 / 1797 ; 18 / 08 / 1798) . \\
\text { - JÓDAR }(22 / 08 / 1797 ; 18 / 08 / 1798) . \\
\text { - GRANADA }(22 / 08 / 1797) . \\
\text { - MÁLAGA }(19 / 09 / 1797) .\end{array}$ \\
\hline $\begin{array}{l}\text { ASISTENCIA A } \\
\text { FIESTAS DE LA } \\
\text { CAPILLA DE } \\
\text { MÚSICA }\end{array}$ & $\begin{array}{l}\text { - LA DE SAN GREGORIO EN SABIOTE (14/06/1796). } \\
\text { - OTRA SIN ESPECIFICAR A SABIOTE (13/05/1797). } \\
\text { - CRISTO DE LA MISERICORDIA DE JÓDAR (22/08/1797). } \\
\text { - HERMANDAD DE NUESTRA SEÑORA DEL ROSARIO DEL CONVENTO DE } \\
\text { SAN ANDRÉS DE ÚBEDA (30/09/1797). } \\
\text { - EN JÓDAR, TORREPEROGIL Y SABIOTE (18/08/1798). }\end{array}$ \\
\hline $\begin{array}{c}\text { CANTO } \\
\text { GREGORIANO } \\
\end{array}$ & JOSÉ CLIMENT DICE ESTAR ESTUDIÁNDOLO (17/01/1795; 06/06/1795). \\
\hline CANTO LLANO & DICE ESTAR ESTUDIÁNDOLO JUAN JOSE DE LOS SANTOS (12/11/1796). \\
\hline $\begin{array}{l}\text { OTRAS CAPILLAS } \\
\text { DE MÚSICA }\end{array}$ & $\begin{array}{l}\text { - CAPILLA DEL HOSPITAL DE SANTIAGO }(20 / 11 / 1757) . \\
\text { - CAPILLA DE LA CATEDRAL DE ORIHUELA }(20 / 12 / 1794) . \\
\text { - CAPILLA DE LA SACRA CAPILLA DEL SALVADOR }(19 / 12 / 1795) . \\
\text { - CAPILLA DE BAEZA }(22 / 08 / 1797) . \\
\text { - SALVADOR DE GRANADA }(22 / 08 / 1797) .\end{array}$ \\
\hline
\end{tabular}

Tabla 2. Resumen de la información en las actas capitulares de la colegiata de Santa María de Úbeda. Elaboración propia, especialmente a partir de la documentación estudiada en el Archivo Ducal de Medinaceli de Sevilla (documentos con fecha completa).

\section{CONCLUSIONES}

Somos conscientes de que el estudio de las capillas de música pertenecientes a catedrales y colegiatas no es ciertamente nada novedoso en la investicación musicológica, pero si nos hemos decidido a realizar este trabajo ha sido única y exclusivamente, en primer lugar, por pensar que bien valía la pena dar a conocer lo sabido por nosotros - después de un largo y laborioso trabajo de búsqueda en los archivos municipales y otros - sobre vida musical de Úbeda en los siglos XVI, XVII y XVIII. En este sentido, destacamos la aportación de importantes y sustanciosas novedades, derivadas esencialmente de la transcripción de las desconocidas actas capitulares custodiadas en el Archivo Ducal de Medinaceli en Sevilla. 
Gracias a estos fondos documentales se completan y hacen presentes la organización de la capilla de música de la colegiata de Santa María y otros tantos aspectos más directamente relacionados con lo musical. En este sentido, y más allá de los datos concretos sobre instrumentos, voces y exámenes, entre otros temas, destacamos la presencia y sintonía de la capilla con la vida religiosa y civil de la ciudad y de otros lugares del arciprestazgo, y otros tantos que no hemos podido desarrollar por la extensión del trabajo, pero que sin duda abren caminos para nuevas investigaciones. Por ejemplo, resultaría de interés indagar en las relaciones con otras capillas - más allá del simple envío de pregones a las capillas colegiales y catedralicias - , citadas en otros acuerdos no directamente relacionados con la música, de Jaén, Baeza, Granada, Guadix, Baza, Lorca, Murcia, Orihuela, Córdoba, Osuna, Antequera, Málaga, Sevilla, Cádiz, Castellar y Almería.

No era objetivo de este trabajo presentar el funcionamiento musical de otras colegiatas, de las que conocemos abundante bibliografía, aunque pensamos que las aportaciones sobre los aspectos estudiados aquí facilitarán la amplición de su conocimiento o su ratificación. No dudamos que sería importante y necesario proceder, por nosotros mismos o por otros, a un seguimiento de los maestros de capilla presentados. Aspecto importante junto a otros, así lo consideramos, sería también profundizar en la situación y reconocimiento social de los músicos y de la influencia de la situación económica de la colegiata y de la ciudad en estos aspectos.

Por desgracia, no se ha conservado ningún inventario de los bienes de Santa María, algo que hubiese resultado providencial para conocer los textos musicales de la capilla. Sí conocemos varios de la capilla del Salvador, más concretamente, uno fechado en 1568, en el que se mencionan libros de polifonía con obras renacentistas de Josquin Desprez ("Joaquin" en el documento), Cristóbal de Morales, Nicolas Gombert y Andreas de Silva:

[...] diez y siete cuerpos de libros de cantoria grandes para el coro con sus bisagras a los lados y en medio son los de canto llano, un libro de canto de organo las misas de Joaquin enquadernado en cartones, tres pasioneros encuadernados en bezerro, dos cuadernos de libros de cantos de organo de las misas de Morales enquadernados en cartones, un quaderno de cantos de órnano de motetes y hymnos, otro quaderno de difuntos de Morales con inmitatorio de figuntos, otros cuatro libretes de motetes de Andres de Silva, otros quatro libretes de motetes de Gom- bert y otros auctores, otros cinco libretes de motetes estrangeros, un quaderno de papel de marca mayor con officios de maytines y el tedeum laudamus, otro libro nuevo grande de misas y motetes con cartones blancos. ${ }^{34}$

En definitiva, a lo largo de estas páginas, hemos pretendido aproximarnos al conocimiento de la capilla de música de Santa María de los Reales Alcázares de Úbeda para facilitar la posible continuación y crecimiento de su estudio. Creemos que esto era algo que una ciudad como Úbeda se merece.

\section{APÉNDICES}

APÉNDICE 1: Contenido de las Actas Capitulares (6 de noviembre de 1751 a 31 de marzo de 1759) de la colegiata de Santa María de Úbeda conservadas en el Archivo Ducal de Medinaceli en Sevilla. ${ }^{35}$

Cabildo de 6 de noviembre de 1751: Se nombra como arpista a don Gaspar [sic], vecino de Baeza, en sustitución del arpista natural, don Diego de Roa, por su impedimento; al titular se le mantiene la renta de la capilla, al sustituto la demás renta y los percances.

Cabildo de 23 de diciembre de 1751: Memorial del sochantre don Bartolomé de Almagro, alegando que se le deben ciertas cantidades de trigo y maravedíes por parte del señor chantre. Se acuerda que por los señores contadores se saque de las tercias de la ciudad el trigo que sea necesario para la paga y satisfacción de la renta del año y, para lo demás que pide, lo haga donde convenga.

Cabildo de 20 de enero de 1753: Memorial de Luis de Arjona pidiendo por merced, alegando para ello algunos servicios realizados en la iglesia, además de los de su cargo de músico, se le conceda la limosna que el cabildo fuese servido de hacerle. Se acuerda se le den cuarenta y cuatro reales y que para ello acuda al administrador don Juan de Gila.

\footnotetext{
${ }^{34}$ A.H.M.Ú., F.P.N., 995, fols. 170-189.

35 En la transcripción de los acuerdos capitulares hemos preferido respetar escrupulosamente la ortografía original de los nombres propios. También mantenemos el tratamiento de "don" porque así aparece en el texto, diferenciándo otras ocasiones en las que no se usa; la presencia del tratamiento nos sitúa ante una clara señal de respeto y consideración hacia las personas a las que se les aplica.
} 
Cabildo de 18 de mayo de 1754: Memorial del sochantre don Bartolomé de Almagro en el que manifiesta que por el administrador de la mesa capitular no se le paga un resto de maravedíes que se le debe de su renta correspondiente al año 1753 . Se acuerda el pago de la deuda.

Cabildo de 14 de marzo de 1755: Memorial de Sebastián de Contreras, segundo sochantre, manifestando sus necesidades y tener embargadas las rentas de su capellanía; solicita algún socorro por parte del cabildo así de presente como de renta anual. El cabildo acuerda que para la asignación de la renta se informe primero al tesorero de si sirve o no para la asistencia y uso de su empleo y; que cuando esto esté hecho, se dará providencia. Por ahora se le dan de socorro dos ducados y otros dos a Lorenzo de Orea, hijo del bajonista Francisco Molina.

Cabildo de 14 de marzo de 1755: Se ve otro memorial de Luis de Taxona en que suplica al cabildo se sirva librarle algunos maravedíes, lo que fuere servido, por tener pendientes atrasos y dificultad para mantenerse.

Cabildo de 14 de marzo de 1755: El Cabildo decreta que de ahora en adelante se le haga saber al maestro de capilla les mande a todos los músicos que asistan a todas las funciones que ocurran en la iglesia o de lo contrario se les multará.

Cabildo de 15 de enero de 1757: Memorial de Francisco de Molina, bajonista, pidiendo que a su hijo Lorenzo de Orea, empleado en la música a media parte, se le dé hasta completar tres cuartas partes de música como las tiene Sebastián de Contreras, empleado en ella. El cabildo aprueba que el memorial vuelva a presentarse en un cabildo en el que estén todos sus componentes.

Cabildo de 5 de marzo de 1757: Memorial del bajonista Francisco de Molina pidiendo licencia para ir a Guadix a opositar a la plaza de bajonista. El cabildo le da licencia por el tiempo que necesitara.

Cabildo de 12 de marzo de 1757: Memorial del sochantre pidiendo licencia para opositar a la plaza de sochantre de Guadix. El cabildo concede la licencia, pero imponiendo que debía estar de vuelta en la ciudad en la víspera del Domingo de Ramos.

Cabildo del 13 de agosto de 1757: Acuerdo para fijar edictos buscando pretendientes para cubrir la plaza de sochantre con término de treinta días y para hacer impresos que se manden a las catedrales y colegiatas que parecieren convenientes.
Cabildo de 11 de octubre de 1757: El señor tesorero informa que se ha convocado el cabildo para proceder al nombramiento de sochantre, una vez celebradas las pruebas en las que el maestro de capilla ha estado presente y de las que ha realizado un informe sobre la suficiencia y habilidad de los candidatos. El cabildo procede a una votación secreta de la que sale elegido don Bernardo Antonio de Guzmán, vecino de Granada.

Cabildo de 20 de noviembre de 1757: Memorial de Sebastián de Contreras solicitando se le pague por el administrador lo que el cabildo gustase por el tiempo servido como segundo sochantre.

Cabildo de 20 de noviembre de 1757: Memorial de don Bernardo Antonio de Guzmán afirmando que la plaza de sochantre que se le confirmó es más apropiada para su hermano Joseph de Guzmán respecto a la voz y aplicación. El cabildo, atendiendo a los detalles de la petición, acuerda nombrar sochantre a Joseph de Guzmán y segundo sochantre a don Bernardo Antonio de Guzmán, con las obligaciones de concurrir al coro y al hospital y capilla de Santiago ${ }^{36}$ y con la de asistir al órgano en las ausencias y enfermedades del primer organista, por lo que se le nombra capellán de la capellanía que fundó Francisca de Jódar, con la obligación de ponerla al corriente; asi mismo, se le recibe por capellán mayor, dándole la renta que tenía y gozaba Gregorio Pico.

Cabildo de 12 de marzo de 1759: Memorial del sochantre don Joseph Phelipe de Guzmán despidiéndose del servicio de su empleo. El cabildo acuerda admitir la petición y nombra al tesorero, don Juan Andrés del Santísimo Viedma y Ahumada, y al canónigo, don Francisco de Serna, para que soliciten persona que pueda desempeñar el empleo y den cuenta al cabildo de lo que adelantaren para dar la providencia correspondiente.

Cabildo de 31 de marzo de 1759: Se ven las personas propuestas para el servicio de la sochantría a solicitud de los caballeros comisarios nombrados a tal fin. El cabildo acuerda nombrar como sochantre a don Cristóbal Gómez, vecino de Jaén, elegido por mayor número de votos; igualmente, se acuerda se

${ }^{36}$ El cabildo colegial era por voluntad testamentaria del obispo Cobos patrono del Hospital de Santiago. 
le den los salarios y emulumentos que es costumbre y han tenido sus antecesores.

APÉNDICE 2. Contenido de las Actas Capitulares (24 de marzo de 1792 a 20 de octubre de 1798) de la colegiata de Santa María de Úbeda conservadas en el Archivo Ducal de Medinaceli en Sevilla.

Cabildo de 24 de marzo de 1792: Memorial de Luis Pérez suplicando al cabildo que, hallándose con voz de tenor se estaba instruyendo en canto llano, y deseoso de dedicarse al culto divino, suplica al cabildo dé su permiso para asistir a las horas sin interés alguno más que el de ir adiestrándose. El Cabildo acepta la petición para capellán menor en los términos de la petición.

Cabildo de 14 de abril de 1792: Memorial de don Francisco Javier de Silva y Próspero, del reino de Portugal y clérigo de menores, con voz de crontralto, pidiendo ocupar plaza en la capilla de música. El cabildo lo acepta consignándole de renta 20 ducados, ocho fanegas de trigo al año y parte entera en los percances de la capilla. Podría entrar con sobrepelliz en el coro de cantar.

Cabildo de 16 de junio de 1792: Memorial del salmista Bernardo de Vargas pidiendo licencia para ir a opositar a una plaza de davidazgo ${ }^{37}$ vacante de la catedral de Baeza. Se le concede el permiso.

Cabildo de 7 de diciembre de 1792: Memorial de Millán Sánchez solicitando se le reciba para una de las plazas de músico vacantes en la capilla; obligándose a acudir con sobrepelliz al salmo del coro. El cabildo acuerda que el maestro de capilla informe sobre la pericia y habilidad del suplicante y de la voz que tiene, con intervención y asistencia de los señores capellanes para, en su vista, determinar lo que tenga por conveniente el cabildo.

Cabildo de 7 de diciembre de 1792: Acuerdo para que el secretario escriba a don Francisco de Silva y Próspero, músico de voz de la capilla, amonestándole por las faltas de asistencia al coro y capilla de música, por sus graves y penosos accidentes habituales y el poco o ningún mérito que se ha grangeado en el poco tiempo que sirve en la capilla. El cabildo, por equidad y caridad, acuerda se le siga dando la renta

\footnotetext{
37 Por antonomasia, según el DRAE, el rey David es "El Salmista".
}

asignada hasta final de año, para de ahí en adelante no tener renta alguna; lo que se le notifica para que tome los medios que considere.

Cabildo de 15 de diciembre de 1792: Memorial de Mateo Gómez, músico de voz de la capilla solicitando un aumento de renta sobre los veintiseis ducados anuales que tenía. Se acuerda concederle 20 ducados anuales y cuatro fanegas de trigo.

Cabildo de 15 de diciembre de 1792: Se presenta un informe elaborado por el maestro de capilla, encargado en el cabildo de 7 de diciembre, sobre la voz y habilidad de Millán Sánchez:

Que el suplicante canta por la cuerda de contraalto y en esta parte aunque no llena el c. Solfant. que cita, sube lo bastante para desempeñar los puntos que regularmente tiran estas voces, la suya es agradable y con buena afinación, en la que se perfecionará a fuerza del exercicio. En cuanto a la obligación de el salmeo que promete, vista por todos la gravísima necesidad que hay en el coro de voces, ésta desde luego da motivo para admitir lo que se pretende, mas en razón de informe, no puede menos de hacer a V. M. presente que los contraaltos en manera alguna pueden ni se admiten para llebar la cuerda que por precisión sigue el coro, pues amás de la fuerte violencia que indispensablemente se han de hacer impiden a los demás usar de su cuerda natural. Igualmente hace a V. S. presente tiene un mediano conocimiento en el canto de órgano, el que basta para estudiar por sí, y dar cumplidos los papeles que se le encarguen, éste le facilita el de el canto llano mucho más fácil que áquel. Los instrumentos que menciona, aún no puede informar por no baberse hecho uso de ellos, bien que esto es gracioso en las voces, a no contar particular obligación. Es cuanto debe informar y decir, sugetando desde luego su dictamen a la censura de los más instruidos, como igualmente a lo que V. S. tenga a bien el determinar.

Cabildo de 15 de diciembre de 1792: Se recibe por músico y salmista, después de conocerse el informe realizado por el maestro de capilla, a Millán Sánchez, asignándosele una renta anual de veinte ducados y tres fanegas de trigo.

Cabildo de 15 de diciembre de 1792: Memorial de Francisco Javier Silva y Próspero dando gracias al cabildo y suplicándole que, al estar mejor de la penosa enfermedad que padecía, le permitiese presentarse en el coro y capilla de música para acreditar con la experiencia estar mejor y más sonora su voz. 
Se acuerda por el cabildo que pueda asistir al coro los días que quiera al tener concedida renta hasta finales de año, aunque esto no anula la amonestación realizada en el cabildo del día 7 de diciembre.

Cabildo de 12 de enero de 1793: Memorial del organista Josef Vico solicitando un aumento de renta después de haber trabajado en la iglesia durante once años realizando múltiples tareas. El cabildo acuerda aumentar su renta de veinte ducados y doce fanegas de trigo, dándole al suplicante en dinero hasta quinientos cincuenta reales en los que estarían incluidos los doscientos veinte reales asignados hasta ahora, sin faltarle cosa alguna de la renta de trigo. En el memorial Josef Vico alega como méritos haber ejercido como salmista y sochantre en ausencia y enfermedad de los titulares, estar a cargo de la enseñanza de los niños del coro y ostentar el cargo y pensión del órgano desde que se construyó el nuevo, en el que había procurado adelantar su ciencia, tanto en lo relacionado con la música como en su afinación, conservación y reparos.

Cabildo de 19 de enero de 1793: Memorial del sochantre Julián de Rus solicitando ser liberado por enfermedad. En él se alega el hecho de llevar veintiocho años de servicio con el mayor esmero y celo, sin haber hecho ausencias ni faltas voluntarias en el coro hasta el momento presente, en el que una quiebra de salud, por el mucho trabajo, le ha hecho arrojar sangre del pecho; pide se le libere de oficiar en el coro y se le permita asistir sólo con la obligación de dirigir, gobernar e instruir a los demás, con tal de que se le haga completa presencia en los percances de la capilla de música y se le restituya por ella los intereses de que le han privado desde el día de Todos los Santos, en que tuvo que abandonar el coro enfermo. Se adjunta un certificado médico, firmado por el médico titular don Andrés Antonio Tamayo, justificando la gravedad de la enfermedad, que califica de "hemoptesis" [se refiere a la hemotisis], y el peligro de que se produzca una ulcera de pulmón, amén de la imposibilidad de cantar. Finalmente, el cabildo acuerda, atendiendo a lo solicitado, al certificado médico y al gran mérito del solicitante, que el secretario haga saber al cobrador y distribuidor de la capilla de música se le restituyan todos los maravedíes que no se le han dado desde el día de Todos los Santos hasta el actual en que se le ha de hacer presente en todas las ganancias que tuviera la capi- 1la; igualmente se accede a que asista al coro sin obligación de cantar y sí con la de gobernar, dirigir y enseñar.

Cabildo de 19 de enero de 1793: Enterado el cabildo de la falta de asistencia de algunos miembros de la capilla de música, faltando a los decretos de solicitar licencia por enfermedad o viaje, reproduce el mandato de que esto se observe y cumpla.

Cabildo de 16 de marzo de 1793: Conociendo el cabildo lo nuevo que están trabajando en el coro los seises Julián García y Manuel de Raya, aprueba elevarlos de la "ropa encarnada" y nombrarlos salmistas con una renta de quince ducados anuales y la cuarta parte de los percances de la capilla de música.

Cabildo de 6 de abril de 1793: Queja de sochantre don Julián de Rus sobre la inasistencia de la capilla de música a algunas fiestas en las asistencias que debía hacerle.

Cabildo de 6 de abril de 1793: Se suspende de renta y oficio por dos meses al músico Francisco Toral por "punto que no conviene expresar". De repetirse sería despedido.

Cabildo de 13 de abril de 1793: Memorial de Francisco Toral, músico, solicitando le sea levantada la sanción impuesta. El Cabildo la ratifica en un mes.

Cabildo de 13 de abril de 1793: Acuerdo para que el tesorero imponga multas, según las rentas que tengan asignadas, a los músicos que no asistan los días que tengan obligación de hacerlo.

Cabildo de 13 de abril de 1793: Acuerdo para que el tesorero: "[...] haga comparecer ante sí a Josef de Rojas a quien dará una fuerte y rígida represión sobre algunas faltas de respeto que ha tenido en la iglesia y varias perturbaciones que ocasiona en la capilla de música".

Cabildo de 4 de mayo de 1793: Memorial de Francisco Toral, músico, solicitando se le levante la sanción de renta y asistencia a la capilla de música al estar casi cumplido el mes.

Cabildo de 4 de mayo de 1793: Memorial del sacristan mayor, Francisco de Soria, expresando que por el nuevo tesorero, don Juan Antonio Muñoz de Lago, se le piden fianzas que no le había pedido el anterior, don Juan Andrés de Biedma; fianzas que no ha podido encontrar por más diligencias que ha practicado, en cuya atención se le separa del expresado encargo. Solicita se tenga a bien colocarlo en una plaza de músico de instrumento vacante. 
Cabildo del 17 de mayo de 1793: Se recibe a Francisco de Soria para la plaza de instrumentista vacante en los siguientes términos: su cargo será tocar el violón y cuando se le mande por el maestro tocar también el bajon y la trompa, así como tocar el bajón en las procesiones claustrales para que José de Rojas pudiera tocar la chirimía. Se le consigna de renta la parte entera en los percances de la capilla y de las rentas de la fábrica los diez ducados que ésta daba al violero, más los setenta y dos reales y medio que igualmente se pagaba al bajonista, pero que habían estado suprimidas por la circunstacia de que Soria había de habilitarse más en la música y en el manejo de los instrumentos; y acreditado el adelantaminto con informe del maestro, sería atendido por el cabildo con algún aumento de renta o, por el contrario, despedido.

Cabildo de 8 de junio de 1793: Memorial del sochantre don Julián de Rus solicitando se atienda la petición de jubilación que tenía hecha en el cabildo de 19 de enero, contentándose con la renta que se tuviera a bien asignarle. El cabildo ratifica lo dicho en la reunión de enero y se concede ocho días de término.

Cabildo de 19 de junio de 1793: Memorial del sochantre don Julián de Rus alegando nuevamente determinados méritos (28 años de servicio, renuncia a parte de su renta, que unida con la del tenor y segundo sochantre Francisco Gómez dio para un cantante más para el coro y capilla, sustitución de los maestros de capilla en sus enfermedades) y solicitando nuevamente se le asigne una pensión de jubilación.

Cabildo de 19 de junio de 1793: Acuerdo, después de reflexionar:

[...] con la madurez correspondiente, por el que se concede al sochantre don Julián de Rus en atención a sus méritos la "jubilación con retención de todos los honores, preeminencias y regalías que le son concedidas y ha logrado hasta ahora de tal sochantre, dejándole en libertad para que entre en el coro y asista a los divinos oficios siempre que su salud se lo permita, y en él ocupe el asiento de primer sochantre.

Se le concede una renta de cuarenta ducados anuales y perpetuos.

Cabildo de 13 de julio de 1793: Memorial del maestro de capilla don Francisco de Paula González solicitando permiso para plantar de vid y olivas el haza de dieciocho cuerdas de tierra de la capellanía que fun- dó doña Francisca de Jódar. El cabildo remite la petición a los interventores para que informen de la utilidad de lo pretendido.

Cabildo de 13 de julio de 1793: Acuerdo para disponer edictos en las iglesias de costumbre por un término de cuarenta días para cubrir la plaza de sochantre. ${ }^{38}$

Cabildo de 18 de enero de 1794: Memorial de Mateo Gómez, músico contralto, solicitando por caridad un aumento de su renta de veinte ducados y cuatro fanegas de trigo anuales. Se desestima.

Cabildo de 18 de enero de 1794: Memorial de Francisco de Soria, músico de bajón y trompa, solicitando por caridad el aumento de los catorce ducados de renta que tenía asignados. Se desestima.

Cabildo de 18 de enero de 1794: Memorial del salmista del coro y músico de la capilla Manuel de Raya solicitando un aumento de su renta "por el mucho trabajo que tiene". Se le aumenta con una cuarta parte de los percances de la capilla de música, de manera que tenga media ración.

Cabildo de 18 de enero de 1794: Memorial del salmista Julián García solicitando aumento de renta "por el grande y diario trabajo" que tiene. Se le aumentan cinco ducados sobre los quince que tenía y una cuarta parte de los percances de la capilla de música sobre la otra cuarta parte que ya poseía.

Cabildo de 18 de enero de 1794: Se trata el tema de la vacante en la sochantría y la sustitución que de ella se hace por algunos salmistas y se discute sobre si el chantre estaría obligado a pagar a estos salmista la renta propia del sochantre. Se acuerda consultar el asunto a los gobernadores del obispado.

Cabildo de 12 de abril de 1794: Acuerdo de conceder una gratificación de cien reales a Francisco Paredes, oficial amanuense de la Contaduría y músico de la capilla, por el trabajo realizado en el libro nuevo de memorias.

Cabildo del 10 de mayo de 1794: Memorial del músico Francisco Toral sobre la multa de diez reales impuesta por la inasistencia a la comunión general del Jueves Santo. Justifica su ausencia por el hecho de

\footnotetext{
38 En otros acuerdos, referidos a distintos temas, se citan como iglesias catedrales y colegiales de costumbre para el envío de pregones: Jaén, Baeza, Granada, Guadix, Baza, Lorca, Murcia, Orihuela, Córdoba, Osuna, Antequera, Málaga, Sevilla, Cádiz, Castellar y Almería.
} 
ser también sacristán de la parroquial de San Pedro. Se aprueba que debe pedir permiso para asistir a San Pedro los Jueves Santos y, en cuanto a la multa, debía decidir el tesorero.

Cabildo de 11 de octubre de 1794: Ante la falta de sochantre y la no presentación de candidatos a la plaza, a pesar de los edictos mandados, se acuerda proponer a don Julián Rus, sochantre jubilado, la posibilidad de entrar en el coro principalmente en los días festivos, si la salud se lo permitiere.

Cabildo de 11 de octubre de 1794: Acuerdo, ateniéndose a lo dispuesto en el título undécimo de los estatutos y a lo acordado en diversos cabildos, para recordar que la capilla de música debe pedir licencia para salir fuera de Úbeda a servir los percances que les ocurran en otros pueblos. Debía trasladarse al maestro de capilla.

Cabildo de 18 de octubre de 1794: El sochantre jubilado don Julián de Rus declina la petición de asistir al coro alegando no estar de animo ni poco ni mucho.

Cabildo de 20 de diciembre de 1794: Memorial de don Agustín Climent, natural de la villa de Beniganím, arzobispado de Valencia, salmista de la catedral de Orihuela, solicitando la plaza de sochantre.

Cabildo de 22 de diciembre de 1794: Visto el informe emitido por don Francisco de Paula González, maestro de capilla, sobre la suficiencia de don Agustín Climent, se le recibe como sochantre en los mismos términos y renta que su antecesor, Julián de Rus, pero sin los cuarenta ducados dados a éste por jubilación en junio de 1793.

Cabildo de 22 de diciembre de 1794: Acuerdo para el aumento de la renta hasta treinta ducados (20 del caudal de la mesa y diez del de la fábrica) a los salmistas y músicos Millán Sánchez, Julián García y Manuel de Raya. El aumento tendría efecto desde enero de 1795. Al primero se le cesa en lo consignado de trigo desde el mismo día; los segundos recibirían ración entera en todos los percances de la capilla.

Cabildo de 22 de diciembre de 1794: Atendiendo el cabildo a los "buenos servicios, aplicación y excelente voz" de Mateo Gómez, músico contralto, se le aumenta la renta de veinte a cuarenta ducados a partir del 1de enero de 1795, pero cesando ese mismo día el consignado de trigo que recibe.

Cabildo de 17 de enero de 1795: Memorial de don Josef Climent solicitando permiso para entrar en el coro a instruirse con mayor facilidad, manifestando algu- nos principios de voz y estar estudiando canto gregoriano. Se le recibe y se le nombra capellán de menores con los emulomentos correspondientes.

Cabildo de 6 de junio de 1795: Memorial de Julián García, músico y salmista desde 1791, despidiéndose para ir a servir al rey.

Cabildo de 6 de junio de 1795: Despedida de Josef Climent como capellán de coro por haber salido de soldado.

Cabildo de 5 de septiembre de 1795: Memorial de don Francisco Gutiérrez de Contreras, administrador de los bienes del santuario de Madre de Dios, solicitando día y hora para efectuar la redención y entrega de principal del censo que el santuario paga a la obra fundada en la colegial por don Juan Cano Megía para los niños del coro. Se asigna día.

Cabildo de 12 de diciembre de 1795: Se recibe al músico y salmista Julián García en su puesto de la capilla, al haber obtenido licencia de su servicio al rey, con la renta y emolumentos que anteriormente tenía.

Cabildo de 19 de diciembre de 1795: Memorial de Mateo Gómez, músico, dimitiendo de su plaza de contralto por haber conseguido plaza de músico en la Sacra Capilla de El Salvador.

Junta de 14 de mayo de 1796: Información del tesorero sobre la solicitud de licencia de la capilla de música para ir a Torreperogil el próximo día 16.

Junta de 14 de junio de 1796: Información del tesorero sobre la solicitud de licencia de la capilla de música para ir a tocar a la fiesta de San Gregorio en Sabiote.

Cabildo de 1 de octubre de 1796: Despido del salmista Millán Sánchez porque su voz no es apta para el servicio del coro. Se le mantiene como músico, pero perdiendo su asignación de 30 ducados; mantiene el derecho a recibir parte entera en los percances.

Cabildo de 1 de octubre de 1796: Atendiendo a la bondad de la voz del salmista Manuel de Raya, se le nombra segundo sochantre, haciéndole saber, junto al también salmista Julián García, que si se aplican en el cumplimiento y exactitud de sus obligaciones se les recompensaría en proporción a sus méritos.

Cabildo de 1 de octubre de 1796: Discusión sobre si el sochantre, que no estaba ordenado, podía presidir a los capellanes ordenados de primera tonsura y grado. Tras el empate en la votación realizada y para evitar que hubiera (como había pasado recientemente) controversia, disputa y escándalo, se acuerda que de momento el sochantre presida en el coro, 
procesiones y demás actos, ya esté con capa y cetro, ya de sobrepelliz, a todos los capellanes aunque estén ordenados, excepto a los de orden sacro.

Cabildo de 15 de octubre de 1796: Memorial del maestro de capilla y presbítero don Francisco de Paula Gonzalez informando de que ha obtenido una capellanía en la Sacra Capilla del Salvador, pero que es su intención continuar siendo maestro de capilla, proveyendo a la primera de villancicos y a la segunda de sus asistencias, según ya lo hizo cuando fue capellán del Hospital de Santiago. El cabildo, atendiendo a los muchos méritos demostrados en los dieciseis años y medio que lleva ejerciendo de maestro de capilla, accede a mantenerlo en el puesto con los mismos emolumentos o percances devengados hasta el momento.

Cabildo de 12 de noviembre de 1796: Memorial de Juan José de los Santos solicitando poder asistir diariamente al coro y con la capilla a todas las funciones, con el ánimo de adelantar en el canto llano y de órgano que está aprendiendo. Se concede licencia para ello.

Cabildo de 12 de noviembre de 1796: Memorial del sochantre don Agustín Climent solicitando se le franquiciaran las tres fanegas de trigo que el cabildo ordenó le dieran los señores interventores del granero, hallándose en la entrega José de Vico (organista), de quien parece es deudor.

Cabildo de 12 de noviembre de 1796: Se trata de la vacante del magisterio de capilla y de la prorrata de sus emolumentos ${ }^{39}$.

Cabildo de 12 de noviembre de 1796: El tesorero informa de cómo las letras de los villancicos que se han de cantar en los maitines de Navidad, puestos en música por el maestro de capilla, que se presentaron al cabildo en junta particular, se han de mandar a la imprenta.

Cabildo de 23 de diciembre de 1796: Francisco de Soria, bajonista, solicita aumento de renta. Se le aumenta hasta veinticinco ducados anuales.

Cabildo de 23 de diciembre de 1796: Francisco Toral, violinista, manifiesta su indigencia. Se acuerda se le dé lo que sea posible.

\footnotetext{
${ }^{39}$ Creemos que esto es consecuencia del nombramiento como capellán de El Salvador del maestro de capilla don Francisco de Paula González.
}

Cabildo de 23 de diciembre de 1796: Julian García, salmista, solicita aumento de renta. Se le sube de treinta a cuarenta y dos ducados.

Cabildo de 23 de diciembre de 1796: Manuel de Raya, músico y segundo sochantre, solicita aumento de renta. Se le sube de treinta a cuarenta y cinco ducados.

Cabildo de 7 de enero de 1797: Expulsión del violinista Millán Sánchez por no enmendarse en "su siniestro modo de proceder" incluso después de ser reprendido, amonestado y multado. Al parecer la falta va de palabras y comentarios indecorosos y sobre el honor del cabildo y de sus miembros.

Cabildo de 13 de mayo de 1797: El tesorero da cuenta de la solicitud de la capilla de música para salir a la fiesta de Sabiote a celebrar el día siguiente.

Cabildo de 20 de mayo de 1797: Memorial de Antonio López, capellán de coro, solicitando se le permita asistir al coro y a la capilla de música para ejercitar la voz que el mismo define "[...] como voz regular de contralto". Se concede.

Cabildo de 3 de junio de 1797: Memorial de don Pedro Valenzuela y Moya, consorte de doña María de los Dolores Rus, solicitando lo que dejó de cobrar de los cuarenta ducados de su jubilación don Julián de Rus, padre difunto de doña Dolores Rus. La jubilación se acordó en el cabildo de 19 de junio de 1793.

Cabildo de 10 de junio de 1797: Memorial del maestro de capilla y capellán de la Sacra Capilla de El Salvador, don Francisco de Paula González, haciendo dimisión de su magisterio. El cabildo acepta la dimisión y da órdenes para comprobar la dotación de dicho magisterio y, en su vista, deliberar lo que conviniese.

Cabildo de 1 de julio de 1797: Reclamación del sochantre y salmista (posiblemente Manuel de Raya) del medio año que se le debía de sus rentas. Se acuerda que se acuda a los señores distribuidores, a quienes corresponden los pagos.

Cabildo de 22 de agosto de 1797: El señor tesorero, don Juan Antonio Muñoz de Lago, ante la vacante de la maestría de la capilla de música, por dimisión de don Francisco de Paula González, pide se delibere la forma de no perjudicarla ni despojada del derecho y posesión en que se haya de ser preferida a otra cualquiera en asistir y servir todas las funciones o fiestas de esta ciudad y pueblos de su arciprestazgo, como se intenta por los comisarios de la fiesta del Cristo de la Misericordia de Jódar, que ya tenían 
avisada una capilla de Baeza. Enterado el cabildo, se procede a dar a conocer un memorial de don Dionisio Rodríguez y Lloveras, procedente de El Salvador de Granada, en el que solicita la plaza de maestro de capilla con la obligación de componer las festividades del Corpus y Navidad, con las demás que estuviesen establecidas por costumbre, valiéndose para ello "de la ciencia que alcanza en el manejo de órgano, e instrumentoss de cuerda y ayre". Pide que parte de su renta sea colativa para facilitar ascender al sacerdocio.

Cabildo de 22 de agosto de 1797: Se recibe como maestro de capilla a don Dionisio Rodríguez Lloveras, consignándole las doce fanegas de trigo anuales que recibían sus antecesores y el producto de la capellanía fundada por doña Francisca de Jódar, aneja a la capilla de música; y por lo que respecta a la:

[...] enseñanza de seises, o niños del Coro, desde luego el Cabildo se la concede y fía al expuesto maestro, señalándole por este trabajo sobre los diez y seis ducados que de antiguo vienen consignados, hasta treinta anuales que deverán satisfacérsele de la obra pía de don Juan Cano Megía: cuya admisión, provisión y nombramiento de Maestro de capilla fecha en favor del repetido don Dionisio sea y se entienda con la precisa obligación de que ha de asistir personalmente a todas las funciones festivas y fúnebres que tanto en esta población como en otras de la comarca, ya sean de fuera o dentro de este Arciprestazgo, le ocurran a la capilla, igualmente que a las de esta Iglesia los Domingos y días festivos de todo el año, y más que puedan ocurrir, hecho que deverá estar a la orden y mandato del señor Presidente, componiendo según y en los términos que ofrece en su memorial todas las festividades que an de costumbre en esta Colegial y de las que se le encarguen por el Cabildo, las quales luego que acaben de servir, se han de quedar por de la Iglesia para que en todo tiempo esté provista y surtida de papeles la dicha Capilla de Música, la que contribuirá con dos partes o raciones en los percances, como siempre se ha hecho, y expresa el memorial, al referido maestro, a quien los señores Interventores de la Distributoría, que por tiempo fueren, entregarán annualmente una resma de papel en blanco para que de él paute e inbierta en los Villancicos que componga, el que sea necesario, quedando a su veneficio el que sobrare y siendo de su cuenta la compra del que acaso pueda faltar.

Cabildo de 22 de agosto de 1797: Sobre la presencia de la capilla de música en Jódar para la fiesta del Cristo de la Misericordia, el cabildo faculta al tesorero para que por los medios extrajudiciales que le dicte su prudencia, y no siendo bastantes, por los judiciales, procure dicha presencia y percepción de los emolumentos.

Cabildo de 2 de septiembre de 1797: Memoriales de don Pedro Garzón, músico que fue de la capilla, y de don Pedro Valenzuela y Moyar, músico con voz de contralto, optando a una única plaza vacante. Se admite a los dos con una renta de veinte ducados y ocho fanegas de trigo que:

[...] deverán percebir del caudal de Mesa de por mitad, con la obligación de asistir a las funciones de dentro y fuera de dicha Iglesia, por cuyo cobrador se les contribuya con parte o ración entera a cada uno en los percances [...]. Deveran ejercitarse, el primero, en tañer el violón, bajon y trompa u otro cualesquier instrumento de cuerda y ayre en que esté instruido; y el segundo en canto y, si lo exigiese la necesidad en tañer así mismo algún instrumento de los que maneja; estando ambos a las órdenes, dirección y mandato del Maestro de Capilla y portándose en todo con el celo y aplicación que corresponde, pues aciéndolo assí y verificándose alguna otra vacante o juvilación, acuerda el cabildo se les tenga en ella presentes.

Cabildo de 19 de septiembre de 1797: Se concede licencia al maestro de capilla, don Dionisio Rodríguez y Lloveras, y al músico don Pedro Garzón. Al primero para ir a Granada y traerse su familia y muebles; al segundo, para ir a Málaga a «evaquar cierto asupto de incunvencia». Al maestro se le concede una cantidad de trescientos veinte reales para el viaje y traslado.

Cabildo de 19 de septiembre de 1797: Memorial del maestro de capilla manifestando la gran necesidad, por bien de la capilla y de los músicos, de dos trompas para el mayor lucimiento en las funciones. Para no hacer pesada la carga, se compromete a pagar la mitad del coste de sus propios intereses. La otra mitad corresponde al caudal de la mesa capitular.

Junta de 30 de septiembre de 1797: Permiso para que la capilla de musica acuda a solennizar la fiesta de la hermandad de Nuestra Señora del Rosario que se servía por los caballeros de la ciudad en el convento de San Andrés. La petición la hace don Josef Messía Chacón, su mayordomo, ofreciendo la cantidad de cien reales como en años anteriores. A la vista de 
esto, el señor Corregidor había puesto providencia mandando a la capilla que, sin perjuicio del derecho de las partes y por evitar novedades que causarían inconvenientes, habiendo en el pueblo tanta concurrencias de gentes forasteras por la celebración de la feria, que asistiese a la fiesta, despues de lo qual se podría pedir lo conveniente. Se acuerda que la capilla acuda a la fiesta por la cantidad de ciento veinte reales, los mismos que se les satisfagan de los haberes de la mesa capitular.

Cabildo de 21 de octubre de 1797: Memorial de Josef de Honrubia, músico con voz de contralto e instrumentista de violín y trompa, solicitando ser admitido en la capilla de música. El Cabildo acuerda que el maestro de capilla informe sobre si hace falta algunas de las indicadas plazas y de su suficiencia.

Cabildo de 31 de octubre de 1797: Se recibe como músico a Josef de Honrubia con las condiciones habituales en cuanto a participación de los percances y obligaciones.

Cabildo de 4 de noviembre de 1797: Solicitud de los músicos don Pedro Garzón y don Pedro Valenzuela para que se les aplique por mitad la plaza vacante por muerte del contralto Juan de la Torre. Se concede a partir de enero próximo; antes, el dinero de la vacante se destina a la compra de un contrabajo, del que carece la capilla, para mayor lucimiento de la misma.

Cabildo de 4 de noviembre de 1797: Se estudia la conveniencia de reducir los situados que gozan los músicos en especie de trigo a la de maravedíes. Se acuerda que el señor tesorero y el señor chantre regulen los precios y se haga lo que convenga.

Cabildo de 16 de diciembre de 1797: Solicitud de Juan José de los Santos para ocupar plaza de segundo violinista por haberse ausentado sin licencia Josef de Honrubia, titular de la plaza. Sería el maestro quien informaría sobre la solución del suplente.

Cabildo de 23 de diciembre de 1797: Se recibe como violinista a Juan José de los Santos consisgnándosele media parte de los percances de la capilla.

Cabildo de 23 de diciembre de 1797: Se recibe como salmista del coro a Luis de Vargas. Se habla de perfeccionarse en canto llano.

Cabildo de 23 de diciembre de 1797: Memorial del maestro de capilla, don Dionisio Rodríguez y Lloveras, solicitando un aumento de renta. Se acuerda un aumento de tres fanegas de trigo y veinte ducados.
Cabildo de 23 de diciembre de 1797: Memorial del segundo sochantre, Manuel de Raya, solicitando un aumento de su renta. Se le aumenta hasta cincuenta ducados.

Cabildo de 10 de febrero de 1798: Memorial del contralto don Pedro Valenzuela y Moya y de su mujer, doña María de los Dolores Rus, hija de don Julián de Rus, que fue sochantre de esta iglesia, presentando el acuerdo capitular de 3 de junio de 1793 con el decreto marginal e informe a él puesto por los señores distribuidores, chantre don Josef Montes y canónigo Merino. Enterado el cabildo, acuerda dar comunicación a los mismos señores para que se transijan con el suplicante en los términos que puedan y juzguen convenientes.

Cabildo de 18 de agosto de 1798: Se da cuenta por el señor tesorero que la capilla de música asistirá en el mes de septiembre a fiestas en Jódar, Torreperogil y Sabiote, villas del arciprestazgo, dando permiso el cabildo.

Cabildo de 20 de octubre de 1798: Memorial del maestro de capilla, don Dionisio Rodríguez Lloveras, manifestando sus vivos deseos de ascender al sacerdocio y suplicando se le proporcionen los medios para su logro, permitiendo que parte de su renta se le haga colativa en los términos practicados en la catedral de Jaén o en los que tuviese a bien el cabildo, que hecho cargo del memorial decreta: que el secretario se informe del obispado o arzobistado al que pertenece el lugar de nacimiento del solicitante y lo que se necesita en él para obtener las sagradas órdenes mayores; al tiempo que se averigue la costumbre observada en semejantes casos en la catedral de Jaén y se busque en el archivo la fundación de la capellania fundada por doña Francisca de Jódar, aneja a la maestría de capilla para estudiar sus cláusulas.

\section{BIBLIOGRAFÍA CITADA}

Almagro García, Antonio. Santa María de los Reales Alcázares de Úbeda. Madrid: Pablo de Olavide-Úbeda Asociación para la Defensa del Patrimonio Cultural Andaluz, 1989

- Santa María de los Reales Alcázares de Úbeda: Arqueología, Historia y Arte. Jaén: El Olivo, 2003a.

—. Artistas y artesanos en la ciudad de Úbeda durante el siglo XVII. Jaén: Universidad de Jaén, 2003b.

_. Pompa y circunstancia en la Úbeda del siglo XVII (Vida, gentes y espacios). Jaén: El Olivo, 2005. 
Almagro García, Antonio y Vicente Miguel Ruiz Fuentes. "Arquitectura e imaginería efímera en las celebraciones religiosas del Siglo de Oro Ubetense". En $I V$ Congreso sobre Humanismo y Renacimiento. Seminario sobre Iconología y Simbolismo en el Siglo de Oro, editado por J. Latorre García y Joaquín Montes Bardo. Úbeda: UNED, 1998, pp. 93-110.

Campos, Jesús y Concepción Camarero, dir. Úbeda, 1972. Según las Respuestas Generales del Catastro de Ensenada. Introducción de Adela Tarifa Fernández. Madrid: Centro de Gestión Catastral y Cooperación Tributaria y Ediciones Tabapres (Grupo Tabacalera), 1994.

Cárdenas, Inmaculada. "La música en la Colegiata de Olivares". Anuario Musical, 26 (1981), pp. 91-129.

Casares Rodicio, Emilio, ed. Diccionario de la música española e hispanoamericana, 10 vols. Madrid: Sociedad General de Autores y Editores, 2002.

Covarrubias, Sebastián de. Tesoro de la lengua castellana o española. Barcelona: Alta Fulla, 1611.

De la Torre Molina, María José. Música y ceremonial en las fiestas reales de proclamación de España e Hispanoamérica (1746-1814). Granada: Universidad de Granada, 2004.

Higueras Maldonado, José. Documentos latinos de Úbeda. Jaén: Instituto de Estudios Giennenses, 1975.

Jiménez Cavallé, Pedro. La música en Jaén. Jaén: Diputación Provincial, 1991.

—. Documentario musical de la catedral de Jaén I. Actas Capitulares. Granada: Centro de Documentación Musical de Andalucía, 1998.

Llordén, Andrés. "Notas históricas de los maestros de capilla de la Catedral de Málaga (1583-1641)". Аnиаrio Musical, 19 (1964), pp. 71-93.
Marín López, Miguel Ángel. “¿Una historia imposible? Música y devoción en Úbeda durante el Antiguo Régimen". En Úbeda en el siglo XVI, dirigido por Arsenio Moreno Mendoza. Jaén: Fundación Renacimiento y Editora El Olivo, 2002, pp. 141-166.

—_. "Úbeda". En Diccionario de la música española e hispanoamericana, 10 vols., editado por Emilio Casares Rodicio. Madrid: Sociedad General de Autores y Editores, 2002, vol. 10, pp. 542-544.

Moscoso y Sandoval, Baltasar de. Constitvciones Synodales del Obispado de Iaén. Hechas y ordenadas por el Ilvstrísimo Señor Don Baltasar de Moscoso y Sandoval, Cardenal de la Santa Iglesia de Roma, Obispo de Iaén, del Consejo de su Magestad, en el Synodo Diocesano, que se celebró en la Ciudad de Iaén, en el año de 1624. Jaén: Pedro Joseph Doblas, 1787.

Ruiz Fuentes, Vicente Miguel. Contratos de obra protocolizados ante los escribanos ubetenses durante el siglo XVI. Tesis doctoral, Universidad de Granada, 1991.

- "El artista en la Úbeda del siglo XVI. Aportaciones a su estudio". En Actas de las I Jornadas de Humanismo y Renacimiento (Úbeda, 14-17 de septiembre de 1992). XX aniversario de la U.N.E.D. Jaén: Universidad Nacional de Educación a Distancia, Centro Asociado 'Andrés de Vandelvira' de la provincia de Jaén, 1994, pp. 59-83.

Torres Navarrete, Ginés de la Jara. Historia de Úbeda en sus documentos: Linajes y hombres ilustres. Úbeda: Gráficas Minerva, 1999.

Recibido: 07.02.2020

Aceptado: 01.05.2020 